Document downloaded from:

http://hdl.handle.net/10251/122921

This paper must be cited as:

Szymkowicz, P.; Benajes, J. (2018). Development of a Diesel Surrogate Fuel Library. Fuel. 222:21-34. https://doi.org/10.1016/j.fuel.2018.01.112

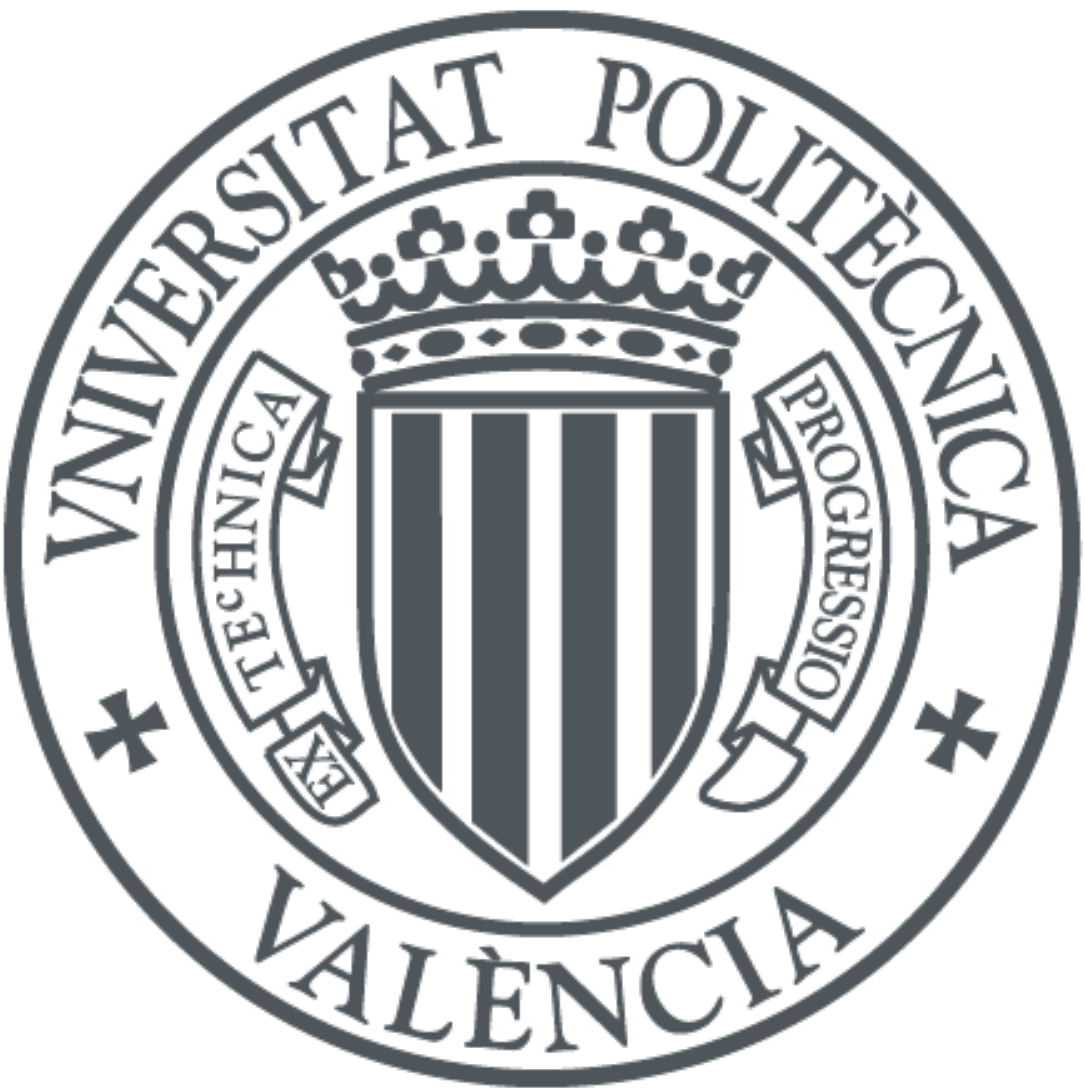

The final publication is available at

https://doi.org/10.1016/j.fuel.2018.01.112

Copyright Elsevier

Additional Information 


\title{
\pm \pm Development of a Diesel Surrogate Fuel Library
}

\author{
Patrick G. Szymkowicz ${ }^{\mathrm{a}}$ and Jesús Benajes ${ }^{\mathrm{b}}$
}

aDiesel Engine Systems Group, Propulsion Systems Research Lab, GM Global Research \& Development, 800 North Glenwood Ave., Pontiac, Michigan 48340-2925 USA

${ }^{\mathrm{b}}$ CMT-Motores Térmicos, Universitat Politècnica de Valencia, Camino de Vera s/n, 46022 Valencia, Spain

\section{Abstract}

Diesel fuel is composed of a complex mixture of hundreds of hydrocarbons that vary globally depending on crude oil sources, refining processes, legislative requirements and other factors. In order to simplify the study of this fuel, researchers create surrogate fuels to mimic the physical and chemical properties of Diesel fuels. This work employed the commercial software Reaction Workbench - Surrogate Blend Optimizer (SBO) to develop a Surrogate Fuel Library containing 18 fuels. Within the fuel library, the cetane number ranges from 35 to 60 (in increments of 5) at threshold soot index (TSI) levels representative of low, baseline and high sooting tendency fuels (TSI $=17,31$ and 48, respectively). The Surrogate Fuel Library provides the component blend ratios and predicted properties for cetane number, threshold soot index, lower heating value, density, kinematic viscosity, molar hydrogen-to-carbon ratio and distillation curve temperatures from $\mathrm{T}_{10}$ to $\mathrm{T}_{90}$. A market petroleum Diesel fuel with a cetane number of 50 and a threshold soot index of 31 was selected as the Baseline Diesel Fuel. The combustion, physical and chemical properties of the Baseline Diesel Fuel were precisely matched by the Baseline Surrogate Fuel. To validate the SBO predicted fuel properties, a set of five surrogate fuels, deviating in cetane number and threshold soot index, were blended and examined with ASTM tests. Good agreement was obtained between the SBO predicted and ASTM measured fuel properties. To further validate the Surrogate Fuel Library, key properties that were effected by altering the component blend ratios to control cetane number and TSI were compared to a set of five market Diesel fuels with good results. These properties included density, viscosity, energy 

supplies Diesel engine researchers and designers the ability to analytically and experimentally vary fuel cetane number and threshold soot index with fully-representative surrogate fuels. This new capability to independently vary cetane number and threshold soot index provides a means to further enhance the understanding of Diesel combustion and design future combustion systems that improve efficiency and emissions.

\section{Key Words}

Diesel fuel, surrogate fuel, Surrogate Fuel Library, fuel properties, cetane number, threshold soot index 


\section{Introduction}

The internal combustion Diesel engine is a highly-versatile power plant for industrial applications and personal mobility. Diesel engines enjoy advantages in efficiency, specific torque, durability, scalability and fuel adaptability. As a result of its importance to society, researchers continue to gain understanding and explore novel combustion systems while engine development engineers work to introduce new Diesel combustion technologies into production [1-5]. The continuous improvement of Diesel engine performance, fuel economy, and emissions is required to achieve the complex needs of society.

Diesel fuel is composed of hundreds of hydrocarbon species that are not well-characterized. Research has shown that Diesel fuel is primarily composed of four hydrocarbon classes: normal-alkanes, iso-alkanes, cyclo-alkanes and aromatics [6-8]. The aromatic hydrocarbons are classified by the number benzene rings in the molecule. Mono-aromatics have a single benzene ring and polycyclic aromatic hydrocarbons (PAH) contain two or more benzene rings. As a result of this complex and undefined composition, researchers create Diesel surrogate fuels for computational and experimental investigations [9-16]. A surrogate fuel is a simple analog created from a small set of well-defined hydrocarbon species. Often surrogate fuels are designed to mimic a subset of Diesel fuel properties. A fully-representative surrogate fuel is designed to replicate numerous physical, chemical and combustion properties of a full-range petroleum Diesel fuel. Such fuel properties include cetane number, threshold soot index, lower heating value, density, kinematic viscosity, surface tension, distillation temperatures and aromatic content.

Surrogate fuels have many applications including spray characterization, chemical kinetic modeling and combustion simulation [17-20]. The application of single-component surrogate fuels, such as n-heptane for Diesel combustion kinetics [21-23] and n-dodecane for Diesel fuel physical properties [24-26], are wellunderstood, highly utilized and greatly valued. Through combustion simulation or experimental work, single-component surrogates have played a significant role to expand the fundamental understanding of Diesel combustion. As engineering tools, single-component surrogates have guided the development of 
conventional and novel Diesel combustion systems. However, single-component surrogates cannot fully represent the physical, chemical and combustion properties of Diesel fuels.

Recent work has increased the number of well-characterized hydrocarbons that are representative of Diesel fuel and potentially useful as surrogate fuel components $[8,18,27-31]$. These efforts have enabled the development of multi-component surrogate fuels that can more closely replicate the properties of Diesel fuel [32-40]. However, as researchers strive to match the combustion and physical properties of Diesel fuel, the complexity of multi-component surrogate fuels has greatly increased. Surrogates assembled with numerous components exceedingly raise the expense of analytical and experimental implementation. For successful industrialization, the tradeoffs between surrogate complexities and predictive combustion simulation accuracy must be understood, rationalized and optimized for the intended application.

Additional forces driving researchers include the understanding that fuel supplies and standards vary regionally and that future Diesel fuels may be considerably different from current fuels. Today, Diesel engine manufacturers encounter a broad range of fuel properties that may influence engine design and the introduction of new technologies. For example, in the United States ASTM D975-16a established a minimum cetane number requirement of 40 [41] whereas in Europe EN 590:2009 required a minimum cetane number of 51 [42]. As a result of variations in fuel properties, Diesel combustion researchers and design engineers require surrogate fuels that provide the capability to independently control two key fuel properties: cetane number and threshold soot index [43]. While doing so other essential Diesel fuel properties such as density, viscosity, heating value and distillation curve temperatures must be reasonably controlled within the range of market fuels. It is believed that the systematic application of multicomponent surrogate fuels with independent control of fuel cetane number and threshold soot index will enhance the fundamental understanding of combustion, efficiency and emissions. At the same time, improved surrogates may provide a means for future improvements in Diesel spray modeling, combustion simulation, and predictive NOx, CO, HC, soot and exhaust particle emissions. 
This investigation creates a library of fully-representative multi-component surrogate Diesel fuels that are appropriate for both exploratory combustion research and direct application to the engine combustion system design process. The effort balanced complexity and accuracy with usefulness and the ability to industrialize the findings.

\section{Objective and Requirements}

The objective of this research was to bring multi-component surrogate fuels closer to routine use by the automotive industry. To this end, the following requirements were placed on the surrogate fuels developed through this investigation:

- The Surrogate Fuel Library must contain a Baseline Surrogate Fuel that closely matches the combustion, physical and chemical properties of a Baseline Petroleum Fuel (market fuel.)

- The Surrogate Fuel Library must contain surrogate fuels with cetane number ranging from 35 to 60 (in increments of 5). In doing so, the library covers potential next-generation fuels which may extend the cetane number range as low as 35 for naphtha-like fuels [44][45] or as high as 60 for synthetic fuels [46][47].

- The library must contain threshold soot index levels representative of low, baseline, and high sooting fuels. Three TSI levels are required to reproduce potential fuel variations and support future investigations that enhance the understanding of soot and particle emissions.

- The combustion and physical properties of the surrogate fuels, namely lower heating value, density, viscosity, surface tension, and distillation curve temperatures, must be representative of market Diesel fuels.

- The number of surrogate fuel components must be kept to a minimum to manage increased complexity, kinetic mechanism size, computational and experimental expenses. 
- To support spray and combustion simulation, the combustion, physical, chemical and temperaturedependent properties of the surrogate components must be available along with validated, detailed kinetic mechanisms.

- To support experimental work, the surrogate components must be available with high-purity, in large quantities, and must meet safety guidelines for storage, blending and handling.

\section{Methodology}

\subsection{Master Kinetic Mechanism}

As mentioned above, there has been and continues to be substantial progress in the development of detailed kinetic mechanisms for surrogate fuel components. This work employed the ANSYS 2015 Model Fuel Library and the accompanying Diesel Fuel Master Kinetic Mechanism [48]. The kinetic mechanism consisted of 55 fuel components, 5,155 chemical species and 31,084 chemical reactions. The mechanism was accompanied by physical, chemical and thermodynamic properties for the fuel components. The fuel component information was utilized to predict surrogate fuel properties and the kinetic mechanism was used for closed-homogenous gas-phase reactor simulations.

\section{2. $\quad$ Surrogate Blend Modeling and Fuel Property Predictions}

A review of the literature revealed several methods to formulate surrogate fuels $[9,49-58]$. In this work, the Reaction Workbench - Surrogate Blend Optimizer (SBO) was employed to model surrogate fuel properties, understand the impact of various compounds on the surrogate properties, determine the blend mixtures needed to achieve the objectives and predict the surrogate properties [56][59]. The SBO utilized a genetic optimization procedure that minimized the differences between user specified fuel properties and their computed values. Upon iteration and convergence, the SBO delivered the surrogate composition that best matched the properties of the target Diesel fuel. To formulate the surrogate fuel the user selects the surrogate fuel components from the available library. Then target values are assigned to the following 
surrogate fuel parameters: Cetane Number (CN), Threshold Soot Index (TSI), Lower Heating Value (LHV), density, viscosity, molar hydrogen-to-carbon ratio (molar $\mathrm{H} / \mathrm{C})$, and distillation curve temperatures from $\mathrm{T}_{10}$ to $\mathrm{T}_{90}$. Weighting factors may be applied to prioritize the role of each parameter in determining the surrogate blend composition. The SBO performs the optimization then reports the user specified target value and the SBO predicted value for each of the parameters listed above. The component fuel property data, surrogate blend optimization methods and property blend models were provided by the Model Fuel Library [48] and the Reaction Workbench Software and User Manual [59].

\subsection{Gas Phase Reactor Simulation}

The ignition process was examined for several pure surrogate fuel components and multi-component surrogate fuel formulations developed with the SBO. This was accomplished with 0-dimensional, transient, closed-homogeneous gas-phase reactor simulations using Chemkin-Pro. The reactor volume was constant and the mass was evenly distributed. The reactor was configured without heat loss and the oxidizer was air (nitrogen and oxygen). The matrix of reactor initial conditions were representative of in-cylinder engine conditions for moderate engine speeds and loads.

\subsection{Fuel Property Measurements}

Market Diesel fuels and surrogate fuels were characterized with the ASTM tests given in Table 1. At a nominal 50 cetane number, ASTM D6890 provided a CN reproducibility of 2.618. ASTM D1322 provided a smoke point reproducibility of $3 \mathrm{~mm}$. Threshold Soot Index (TSI) was calculated from the smoke point measurements using the method defined by Calcote and Manos [60]. 
Table 1. Measured fuel properties and ASTM procedures.

\begin{tabular}{ll}
\hline Fuel Property & ASTM \\
\hline Cetane Number & D6890 \\
Smoke Point & D1322 \\
LHV & D240N \\
Density & D4052 \\
Viscosity & D445 \\
Lubricity & D6079 \\
Hydrogen and Carbon & D5291 \\
Sulfur & D7039 \\
Distillation Temperatures & D86 \\
Hydrocarbon Classes & D1319 \\
Aromatic Content & D5186 \\
Surface Tension & D3825 \\
\hline
\end{tabular}

\subsection{Surrogate Fuel Development}

A baseline Diesel fuel was selected to provide target fuel properties for the development of a baseline surrogate fuel. Then a Diesel surrogate palette containing 13 hydrocarbon species was selected from 55 potential surrogate fuel components. A methodology which included the Reaction Workbench - Surrogate Blend Optimizer was developed to determine the surrogate fuel components and the blend formulations to achieve the objective and requirements in Section 2. Given the surrogate components and the fuel property target values, a baseline surrogate fuel was formulated to closely match the properties of the baseline Diesel fuel. A set of blending rules were developed to guide the formulation of the remaining surrogate fuels. The methodology and predicted fuel properties were validated. A set of surrogate fuels were blended and analyzed using ASTM fuel property tests and the measured properties were compared to the predicted fuel properties.

\subsection{1. $\quad$ Baseline Diesel Fuel}

In this work the baseline Diesel fuel was defined as an available market fuel which could be used for engine and vehicle testing. Several market fuel samples from the USA, Europe and Canada were evaluated. Upon 
review, a market fuel with a cetane number of 50 and a TSI value of 31 was selected as the baseline Diesel fuel. Fuel properties for the baseline and several market Diesel fuels are summarized in Table 2.

Table 2. Measured properties of the baseline Diesel fuel and several market Diesel fuels.

\begin{tabular}{lcccccc}
\hline Property & $\begin{array}{c}\text { Baseline } \\
\text { Fuel }\end{array}$ & $\begin{array}{c}\text { Market } \\
\text { Fuel \#1 }\end{array}$ & $\begin{array}{c}\text { Market } \\
\text { Fuel \#2 }\end{array}$ & $\begin{array}{c}\text { Market } \\
\text { Fuel \#3 }\end{array}$ & $\begin{array}{c}\text { Market } \\
\text { Fuel \#4 }\end{array}$ & $\begin{array}{c}\text { Market } \\
\text { Fuel \#5 }\end{array}$ \\
\hline Cetane Number & 50.9 & 47.6 & 45.0 & 50.4 & 55.8 & 44.2 \\
LHV (MJ/kg) & 43.00 & 42.97 & 43.04 & 43.19 & 43.50 & 43.08 \\
Density (g/ml) & 0.849 & 0.855 & 0.839 & 0.836 & 0.809 & 0.839 \\
Kin. Viscosity (cSt) & 3.063 & 3.094 & 2.266 & 2.631 & 1.821 & 2.257 \\
$\mathrm{~T}_{10}\left({ }^{\circ} \mathrm{C}\right)$ & 227 & 223 & 204 & 187 & 197 & 200 \\
$\mathrm{~T}_{90}\left({ }^{\circ} \mathrm{C}\right)$ & 312 & 314 & 312 & 326 & 269 & 303 \\
Alkanes (\%v/v) & 76.0 & 65.2 & 72.3 & 81.9 & 92.4 & 80.7 \\
Alkenes (\%v/v) & 7.5 & 14.0 & 6.8 & 5.0 & 4.1 & 3.0 \\
Aromatics (\%v/v) & 16.5 & 20.8 & 20.9 & 13.1 & 3.5 & 16.3 \\
\hline
\end{tabular}

\subsubsection{Diesel Surrogate Palette}

The complete list of 55 surrogate components in the 2015 Model Fuel Library were studied. Fuel properties such as cetane number, TSI, LHV, density, viscosity, and boiling point were analyzed. The first task was to reduce the list of 55 components to manageable number. The following guidelines were applied to remove fuel species from consideration:

- Remove hydrocarbon classes that were not typically present in Diesel fuel in substantial volume $(<10 \% \mathrm{v} / \mathrm{v})$. For example, alcohols, ethers, hydrogen, hydrogen sulfide.

- Remove species that had boiling points that were well beyond the distillation temperature range of the target Diesel fuel. For example, most alkenes have low boiling points.

- Remove species that were problematic for blending and conducting experimental investigations. For example, eicosane and naphthalene have high melting points. 
- Use a single species to represent a group of species with similar properties. For example, m-xylene was used to represent several aromatics including benzene, ethylbenzene, o-xylene, p-xylene and n-propylbenzene.

This process of analysis and species removal resulted in a Diesel surrogate palette with 13 hydrocarbon species distributed between four hydrocarbon classes. The surrogate palette and key fuel properties are given in Table 3.

Table 3. Hydrocarbon classes and species selected for the surrogate palette.

\begin{tabular}{|c|c|c|c|c|c|}
\hline & $\begin{array}{l}\text { Cetane } \\
\text { Number }\end{array}$ & TSI & $\begin{array}{c}\text { LHV } \\
(\mathrm{MJ} / \mathrm{kg})\end{array}$ & $\begin{array}{l}\text { Density } \\
(\mathrm{g} / \mathrm{ml})\end{array}$ & $\begin{array}{l}\text { Boiling Point } \\
\left({ }^{\circ} \mathrm{C}\right)\end{array}$ \\
\hline \multicolumn{6}{|l|}{ n-Alkanes } \\
\hline n-Hexadecane & 100 & 6 & 45.23 & 0.773 & 287 \\
\hline n-Dodecane & 83.8 & 6 & 44.23 & 0.750 & 216 \\
\hline n-Decane & 76.7 & 4.5 & 44.56 & 0.730 & 174 \\
\hline n-Heptane & 54.4 & 2.7 & 44.56 & 0.683 & 98 \\
\hline \multicolumn{6}{|l|}{ iso-Alkanes } \\
\hline Heptamethylnonane & 15 & 21 & 44.38 & 0.793 & 240 \\
\hline iso-Octane & 14 & 6.8 & 44.65 & 0.692 & 99 \\
\hline \multicolumn{6}{|l|}{ cyclo-Alkanes } \\
\hline Decahydronaphthalene & 44 & 20 & 43.02 & 0.896 & 187 \\
\hline Methylcyclohexane & 22.5 & 5 & 43.72 & 0.770 & 101 \\
\hline Cyclohexane & 18.5 & 3.5 & 43.98 & 0.779 & 81 \\
\hline \multicolumn{6}{|l|}{ Aromatics } \\
\hline 1-Methylnaphthalene & 0 & 100 & 40.27 & 1.001 & 245 \\
\hline 1,2,4-Trimethylbenzene & 8.9 & 51 & 41.64 & 0.876 & 169 \\
\hline m-Xylene & 2.6 & 51 & 40.81 & 0.864 & 139 \\
\hline Toluene & 2.6 & 40 & 40.72 & 0.865 & 111 \\
\hline
\end{tabular}

\subsubsection{Surrogate Components and Blend Formulation}

A detailed investigation was conducted to identify the surrogate components from Table 3 that could best achieve the requirements set forth in Section 2 and create a baseline surrogate fuel that closely matched properties of the baseline Diesel fuel given in Table 2. The Surrogate Blend Optimizer was used to generate numerous multi-component surrogate fuels. The number of components from the surrogate palette ranged 
from 2 through 8. The target value for $\mathrm{CN}$ was 50 and TSI was 31. The weighting factors for these targets were set at 10.0 because matching the $\mathrm{CN}$ and TSI were given the highest priority. The measured values for the baseline Diesel fuel were used as the target values for LHV, density, viscosity, molar $\mathrm{H} / \mathrm{C}$, and $\mathrm{T}_{10}$ to $\mathrm{T}_{90}$. A weighting factor of 1.0 was used for these targets. Sensitivity studies were conducted to identify the surrogate palette components that had small effects on matching the baseline Diesel fuel properties. The influences could have been considered small due to the impact of the component properties or a lesser component volume fraction determined by the optimizer $(<5 \% \mathrm{v} / \mathrm{v})$.

The investigation concluded that a four-component surrogate best achieved the requirements given in Section 2. The four components included n-hexadecane to represent the n-alkane class, 2,2,4,4,6,8,8heptamethylnonane to represent the iso-alkane class, decahydronaphthalene to represent the cyclo-alkane class, and the aromatics were represented by 1-methylnaphthalene. General information and properties for the four surrogate components are provided in Table 4. The volume fractions for the baseline surrogate fuel components were: $\mathrm{n}$-hexadecane $=0.37$, heptamethylnonane $=0.33$, decahydronaphthalene $=0.18$ and 1 methylnaphthalene $=0.12$. The SBO predicted properties for the baseline surrogate fuel closely matched the ASTM measured properties for the baseline Diesel fuel. The results are provided in Table $\mathbf{5}$ and discussed in Section 4.1. 
Table 4. The four hydrocarbon species used to formulate the surrogate fuels.

\begin{tabular}{lcccc}
\hline Parameter & n-Hexadecane & $\begin{array}{c}\text { Heptamethyl- } \\
\text { nonane }\end{array}$ & $\begin{array}{c}\text { Decahydro- } \\
\text { naphthalene }\end{array}$ & $\begin{array}{c}\text { 1-Methyl- } \\
\text { naphthalene }\end{array}$ \\
\hline Hydrocarbon Class & n-Alkane & iso-Alkane & cyclo-Alkane & Aromatic \\
Chemical Formula & $\mathrm{C}_{16 \mathrm{H}_{34}}$ & $\mathrm{C}_{16 \mathrm{H}} \mathrm{H}_{34}$ & $\mathrm{C}_{18}$ & $\mathrm{C}_{11} \mathrm{H}_{10}$ \\
Molecular Weight (g/mol) & 226.45 & 226.45 & 138.25 & 142.2 \\
CAS Number & $544-76-3$ & $4390-04-9$ & $91-17-8$ & $90-12-0$ \\
Purity (\%) & 99 & 87 & 99 & 97 \\
Cetane Number & 100 & 15 & 44 & 0 \\
Threshold Soot Index & 6 & 21 & 20 & 100 \\
LHV (MJ/kg) & 45.23 & 44.38 & 43.02 & 40.27 \\
Density (g/ml) & 0.773 & 0.793 & 0.896 & 1.001 \\
Kinematic Viscosity (cSt) & 3.975 & 4.293 & 2.254 & 2.861 \\
Boiling Point ( $\left.{ }^{\circ} \mathrm{C}\right)$ & 287 & 240 & 187 & 242 \\
\hline
\end{tabular}

Following the development of baseline surrogate fuel, blending rules were created to guide the formulation of the remaining surrogates. First, the volume fractions of $n$-hexadecane and heptamethylnonane would be tuned to control cetane number while the sum of the volume fractions for these two components should be held close to 0.7. Second, the volume fractions of decahydronaphthalene and 1-methylnaphthalene would be adjusted to control TSI while the sum of the volume fractions for these two components should be held near to 0.3 . And finally, while formulating the surrogate fuels a general tolerance of \pm 1 was established for cetane number and TSI. This tolerance was set within the ASTM measurement reproducibility for these properties. The application of these blending rules moderated the fuel properties to reasonable and consistent values as the blend formulations were adjusted to independently control fuel cetane number and TSI.

The blending rules and the Surrogate Blend Optimizer were then used to formulate the fuels for the Surrogate Fuel Library. For this exercise, the SBO input target values were the four surrogate component volume fractions instead of the fuel properties. As a result, the SBO simply calculated the fuel properties for the input formulation (there was no optimization). With this technique, the blending rules were easily applied and formulations were developed for each surrogate fuel. The volume fractions of $\mathrm{n}$-hexadecane 
and heptamethylnonane were adjusted to achieve the target $\mathrm{CN}$ values and the volume fractions of decahydronaphthalene and 1-methylnaphthalene were adjusted to achieve the target TSI values. Throughout the process, the remaining predicted properties (LHV, density, etc.) were monitored. To create surrogate fuels with the lowest possible sooting tendency, a set of fuels were formulated without 1methylnaphthalene. Hence, these surrogates contained three components that were all saturated hydrocarbon compounds (no carbon-carbon double bonds or benzene rings).

A naming convention was created to identify the surrogate fuels. The convention used the prefix $\mathrm{CN}$ followed the target cetane number, an underscore, then the prefix TSI followed by the target threshold soot index value. Thus, baseline surrogate fuel that had a target CN of 50 and a target TSI of 31 was named CN50_TSI31.

\section{Results}

\subsection{Baseline Diesel and Baseline Surrogate Fuel Property Comparison}

ASTM fuel property test results for the baseline Diesel fuel and the baseline surrogate fuel CN50_TSI31 are provided in Table 5. While formulating CN50_TSI31, matching the target cetane number and target TSI were given the highest priority (weighting factor $=10$ ) followed by density, heating value and viscosity. There was less flexibility towards matching the distillation curve. This was a result of the decision to limit the surrogate to four components coupled with difficulties handling hydrocarbons with high melting points. A lubricity improver was added to the surrogate fuel at a concentration of $100 \mathrm{ppm}$ to achieve the lubricity of the market Diesel fuel. 
Table 5. ASTM measured properties of the baseline Diesel fuel compared with the ASTM measured and

239 SBO predicted properties of the baseline surrogate fuel CN50_TSI31.

\begin{tabular}{lcccc}
\hline Fuel Property & Units & $\begin{array}{c}\text { Baseline } \\
\text { Diesel Fuel } \\
\text { (Measured) }\end{array}$ & $\begin{array}{c}\text { Baseline } \\
\text { Surrogate Fuel } \\
\text { (Measured) }\end{array}$ & $\begin{array}{c}\text { Baseline } \\
\text { Surrogate Fuel } \\
\text { (Predicted) }\end{array}$ \\
\hline Cetane Number & $\mathrm{mm}$ & 50.9 & 50.1 & 49.9 \\
Smoke Point & 19.0 & 18.8 & 31.5 \\
Threshold Soot Index & $\mathrm{MJ} / \mathrm{kg}$ & 43.004 & 33.7 & 43.81 \\
Lower Heating Value & $\mathrm{g} / \mathrm{ml}$ & 0.849 & 0.837 & 0.821 \\
Density at $15^{\circ} \mathrm{C}$ & $\mathrm{CSt}$ & 3.06 & 2.41 & 2.728 \\
Kinematic Viscosity at $40^{\circ} \mathrm{C}$ & $\mathrm{cSt}$ & 0.99 & 0.89 & \\
Kinematic Viscosity at $120^{\circ} \mathrm{C}$ & $\mathrm{N} / \mathrm{m}$ & 0.0312 & 0.0273 & \\
Surface Tension & $\mu \mathrm{m}$ & 489 & 440 & \\
Lubricity - Wear Scar Diameter & $\mathrm{\circ} \mathrm{C}$ & 226.8 & 220.6 & 229.2 \\
T10 & ${ }^{\circ} \mathrm{C}$ & 311.7 & 272.4 & 277.7 \\
T90 & $\% \mathrm{v} / \mathrm{v}$ & 76.0 & 82.7 & 88.0 \\
Alkane Hydrocarbons & $\% \mathrm{v} / \mathrm{v}$ & 7.5 & 4.9 & 12.0 \\
Alkene Hydrocarbons & $\% \mathrm{v} / \mathrm{v}$ & 16.5 & 12.4 & \\
Aromatic Hydrocarbons & $\% \mathrm{~m} / \mathrm{m}$ & 16.4 & 16.4 & \\
Total Aromatics & $\% \mathrm{~m} / \mathrm{m}$ & 16.2 & 0.4 & \\
Mono-Cyclic Aromatics & $\% \mathrm{~m} / \mathrm{m}$ & 0.2 & 16.0 & \\
Polycyclic Aromatics & $\% \mathrm{~m} / \mathrm{m}$ & 86.38 & 86.07 & \\
Carbon Content & $\% \mathrm{~m} / \mathrm{m}$ & 13.42 & 13.51 & \\
Hydrogen Content & $\mathrm{ppm}$ & 9.4 & 1405 & \\
Sulfur Content & $\mathrm{molR}$ & 1.85 & 1.87 & \\
H/C Molar Ratio & & 14.58 & 14.60 & \\
Stoichiometric A/F Ratio & & & & \\
\hline
\end{tabular}

The baseline Diesel fuel had a measured cetane number of 50.9 compared to 50.1 for CN50_TSI31. At a nominal 50 cetane number, ASTM D6890 provided a CN reproducibility of 2.618 [61]. The ASTM measurements suggest the baseline Diesel fuel and surrogate CN50_TSI31 match cetane number within the reproducibility of the test procedure.

ASTM D1322 provided a smoke point reproducibility of $3 \mathrm{~mm}$ [62]. The fuels test result show a smoke point of $19 \mathrm{~mm}$ for the baseline Diesel and $18.8 \mathrm{~mm}$ for CN50_TSI31. A match within the measurement reproducibility. The TSI for the baseline Diesel fuel was 31.0 compared to 33.7 for the surrogate CN50_TSI31. 
The baseline Diesel LHV was $43.004 \mathrm{MJ} / \mathrm{kg}$ while surrogate CN50_TSI31 was $42.857 \mathrm{MJ} / \mathrm{kg}$. The difference between the Diesel and surrogate fuels was only $0.3 \%$. ASTM D240N provided a reproducibility of 0.4 $\mathrm{MJ} / \mathrm{kg}$ [63]. With an absolute difference of only $0.147 \mathrm{MJ} / \mathrm{kg}$ between the two fuels, it was concluded that CN50_TSI31 matched the lower heating value of the baseline Diesel fuel within the reproducibility of the measurements.

ASTM tests reported densities of $0.849 \mathrm{~g} / \mathrm{ml}$ for the baseline Diesel and $0.831 \mathrm{~g} / \mathrm{ml}$ for CN50_TSI31; a difference of only $2.1 \%$. Typical Diesel fuel has a nominal density of $0.85 \mathrm{~g} / \mathrm{ml}$ and ranges between 0.82

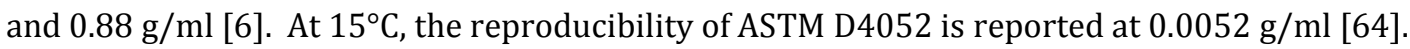

At $40^{\circ} \mathrm{C}$, the kinematic viscosity of the baseline Diesel fuel was $3.06 \mathrm{cSt}$ compared to $2.41 \mathrm{cSt}$ for surrogate CN50_TSI31. ASTM D975 established a viscosity requirement of 1.9-4.1 cSt for No.2-D Diesel fuel [41]. Diesel fuel viscosity drops rapidly as temperature increases. At $120^{\circ} \mathrm{C}$, the baseline Diesel value dropped to $0.99 \mathrm{cSt}$ and the surrogate fuel dropped to $0.89 \mathrm{cSt}$. Under fully-warmed-up engine operating conditions, this small difference in viscosity is considered to be negligible.

The surface tension of the baseline Diesel was measured at $0.0312 \mathrm{~N} / \mathrm{m}$ while the CN50_TSI31 surrogate was $0.0273 \mathrm{~N} / \mathrm{m}$; a $12 \%$ difference. In other works, Wang, et al. reported a Diesel fuel surface tension of $0.028 \mathrm{~N} / \mathrm{m}$ which was very close to surrogate CN50_TSI31 [65]. Ra, et al. investigated the effects of fuel properties with Diesel and Biodiesel surrogates and reported approximately $0.026 \mathrm{~N} / \mathrm{m}$ for a Diesel surrogate fuel [66]. At $25^{\circ} \mathrm{C}$, the DIPPR correlation calculates the surface tension of n-dodecane to be 0.025 $\mathrm{N} / \mathrm{m}$ [67]. The surface tension of CN50_TSI31 is well within the range of previously reported values.

The distillation curves for the baseline Diesel and surrogate fuels are presented in Figure 1. Test results showed reasonable agreement over the entire distillation temperature range. Surrogate CN50_TSI31 had a $\mathrm{T}_{10}$ distillation temperature that was only $6^{\circ} \mathrm{C}$ less than the baseline Diesel fuel. In the mid-range from $\mathrm{T}_{30}$ to $\mathrm{T}_{80}$ the surrogate was $35^{\circ} \mathrm{C}$ lower. At the final boiling point, CN50_TSI31 was $51^{\circ} \mathrm{C}$ lower than the baseline 
Diesel fuel. The lower distillation temperatures for CN50_TSI31 resulted from the decision to limit the number of surrogate components to four and exclude n-alkanes larger than n-hexadecane. The SBO predicted distillation temperatures for surrogate CN50_TSI31 were slightly higher than the ASTM measured values for the surrogate fuel.

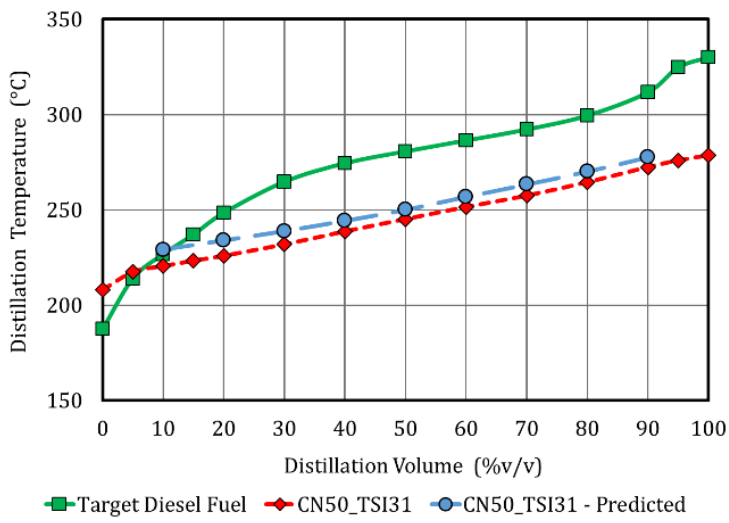

Figure 1. Distillation curves for the baseline Diesel fuel and surrogate CN50_TSI31.

The surrogate and baseline Diesel fuels were characterized by two ASTM test methods that provided a simplified view of the hydrocarbon classes. On a volume basis, CN50_TSI31 had slightly more alkanes than the baseline Diesel fuel. The surrogate was precisely blended to contain $88 \%$ alkanes while the test results showed $82.7 \%$ for the surrogate and 76\% for the baseline Diesel fuel. ASTM D1319 test showed that the baseline Diesel fuel contained 7.5\% alkenes. The surrogate was formulated without alkenes. However, test results showed the surrogate fuel contained $4.9 \%$ alkenes. This may have resulted from detection errors. There is also the possibility that some alkenes were present as impurities in the surrogate components. If alkenes were present in the surrogate fuel, the concentrations were small and can be neglected for the purposes of this work.

On a volume basis, CN50_TSI31 contained slightly less aromatics than the baseline Diesel fuel. CN50_TSI31 was precisely blended to contain $12 \% \mathrm{v} / \mathrm{v}$ aromatics which is in very good agreement with the ASTM result. 
On a mass basis, the total aromatics were the same for both fuels. This was an expected result because the baseline Diesel fuel contained mono-cyclic aromatics which generally have lower densities than polycyclic aromatics. CN50_TSI31 was formulated with 1-methylnaphthalene; a polycyclic aromatic with a density that is roughly $15 \%$ higher than many mono-cyclic aromatics.

The fuel carbon and hydrogen content matched very well with less than $1 \%$ difference. The Diesel fuel had $9.4 \mathrm{ppm}$ sulfur while the surrogate fuel contained $1405 \mathrm{ppm}$. Testing revealed that 1-methylnaphthalene was the source of the sulfur. While present, the sulfur concentration was considered too low to have a significant impact on the spray, combustion and emission performance of the surrogate fuels.

\subsection{Surrogate Fuel Library}

The surrogate fuel names and several predicted properties are given in Table 6. The blend formulations and a complete list of the predicted fuel properties are given in the Appendix. The surrogates are grouped by the TSI value and sorted in order of increasing $\mathrm{CN}$. 


\begin{tabular}{ccccccccc}
\hline Fuel & CN & TSI & $\begin{array}{c}\text { LHV } \\
(\mathrm{MJ} / \mathrm{kg})\end{array}$ & $\begin{array}{c}\text { Density } \\
(\mathrm{g} / \mathrm{ml})\end{array}$ & $\begin{array}{c}\text { Viscosity } \\
(\mathrm{cSt})\end{array}$ & $\begin{array}{c}\text { Molar } \\
\mathrm{H} / \mathrm{C}\end{array}$ & $\begin{array}{c}\mathrm{T}_{10} \\
\left({ }^{\circ} \mathrm{C}\right)\end{array}$ & $\begin{array}{c}\text { T90 } \\
\left({ }^{\circ} \mathrm{C}\right)\end{array}$ \\
\hline CN35_TSI17 & 34.8 & 19.0 & 44.04 & 0.806 & 2.737 & 2.017 & 215 & 262 \\
CN40_TSI17 & 40.7 & 18.2 & 44.09 & 0.805 & 2.724 & 2.017 & 216 & 269 \\
CN45_TSI17 & 45.0 & 17.6 & 44.13 & 0.804 & 2.714 & 2.017 & 217 & 273 \\
CN50_TSI17 & 53.5 & 16.6 & 44.16 & 0.806 & 2.654 & 2.016 & 216 & 278 \\
CN55_TSI17 & 55.2 & 16.2 & 44.23 & 0.803 & 2.692 & 2.016 & 219 & 280 \\
CN60_TSI17 & 60.3 & 15.5 & 44.28 & 0.802 & 2.680 & 2.016 & 221 & 281 \\
& & & & & & & & \\
CN35_TSI31 & 35.5 & 31.1 & 43.74 & 0.820 & 2.756 & 1.897 & 224 & 266 \\
CN40_TSI31 & 40.5 & 32.8 & 43.73 & 0.822 & 2.749 & 1.873 & 227 & 272 \\
CN45_TSI31 & 45.2 & 30.9 & 43.80 & 0.820 & 2.736 & 1.884 & 227 & 275 \\
CN50_TSI31 & 49.9 & 31.5 & 43.81 & 0.821 & 2.728 & 1.872 & 229 & 278 \\
CN55_TSI31 & 55.0 & 30.8 & 43.86 & 0.820 & 2.716 & 1.872 & 231 & 280 \\
CN60_TSI31 & 59.2 & 30.3 & 43.90 & 0.819 & 2.707 & 1.871 & 232 & 282 \\
& & & & & & & & \\
CN35_TSI48 & 34.8 & 48.8 & 43.290 & 0.842 & 2.788 & 1.725 & 239 & 268 \\
CN40_TSI48 & 39.9 & 48.1 & 43.340 & 0.841 & 2.776 & 1.724 & 240 & 272 \\
CN45_TSI48 & 45.0 & 47.5 & 43.380 & 0.840 & 2.765 & 1.724 & 242 & 276 \\
CN50_TSI48 & 48.4 & 48.9 & 43.310 & 0.845 & 2.720 & 1.693 & 242 & 278 \\
CN55_TSI48 & 55.2 & 46.2 & 43.470 & 0.839 & 2.742 & 1.723 & 245 & 280 \\
CN60_TSI48 & 59.9 & 46.8 & 43.490 & 0.839 & 2.734 & 1.711 & 248 & 282 \\
\hline
\end{tabular}

Table 6. The Surrogate Fuel Library containing the SBO predicted fuel properties for 18 fuels with varying CN and TSI. Fuel CN50_TSI31 was developed to match the baseline Diesel fuel.

For a given TSI value (e.g., TSI=17), as the CN increased from 35 to 60 the other fuel properties remained nearly constant. Since the properties of $n$-hexadecane $(\mathrm{CN}=100)$ and heptamethylnonane $(\mathrm{CN}=15)$ were very similar, adjusting their volume fractions to control the $\mathrm{CN}$ had little impact on the other properties. However, the distillation temperatures slightly increased since $n$-hexadecane had a higher boiling point.

For a given CN, as TSI values increased, the LHV and molar $\mathrm{H} / \mathrm{C}$ decreased while the density and distillation temperatures increased. This was primarily due to the impact of increasing the volume fraction of 1methylnaphthalene and decreasing the decahydronaphthalene to control the TSI value. 


\subsection{Predicted and Measured Property Comparison}

The Surrogate Blend Optimizer provided property predictions for each surrogate fuel. It was crucially important to validate predicted fuel properties. To that end, five surrogate fuels were precision blended and characterized with ASTM fuel property tests. The surrogates included the baseline surrogate CN50_TSI31. Fuels CN40_TSI31 and CN60_TSI31 were selected to independently vary the cetane number and fuels CN50_TSI17 and CN50_TSI48 were chosen to independently vary the TSI values. The measured fuel properties were compared to the values predicted by the Surrogate Blend Optimizer.

Figure 2 compares the predicted and measured cetane numbers. As the cetane increased for fuels CN40_TSI31, CN50_TSI31 and CN60_TSI31 the predicted values were precisely matched by the measured results. The differences were within the reproducibility of the ASTM D6890 procedure. For the second comparison, fuels CN50_TSI17, CN50_TSI31 and CN50_TSI48 showed some cetane number variation. Fuel CN50_TSI17 had a predicted cetane number of 53.5 compared to a measured value of 50.1. In the case of fuel CN50_TSI48, the predicted cetane number was 48.4 compared to the measured value of 50.5 . For these five fuels, the average difference between the predicted and measured cetane numbers was only 1.3 and the maximum observed difference between a predicted and measured cetane number was 3.4.

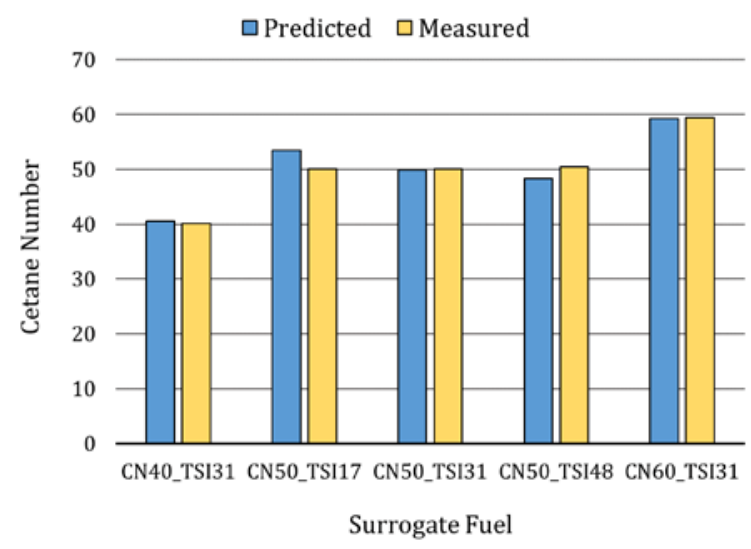


Figure 2. A comparison of predicted and measured cetane numbers for five surrogate fuels.

\subsubsection{Threshold Soot Index}

The TSI results are given in Figure 3. For the first comparison, as cetane number was increased for fuels CN40_TSI31, CN50_TSI31 and CN60_TSI31, the measured TSI values were slightly greater than the predicted values. For the second comparison, as TSI values were increased from 17 to 48 (fuels CN50_TSI17, CN50_TSI31 and CN50_TSI48) the predicted and measured values were in good agreement. For all of the fuels, the average difference between the predicted and measured TSI values was 2.0 and the maximum observed difference between a predicted and measured TSI value was 2.7. These results were considered to be within the reproducibility of the TSI value when obtained from the ASTM smoke point measurement and calculated with the method defined by Calcote and Manos [60].

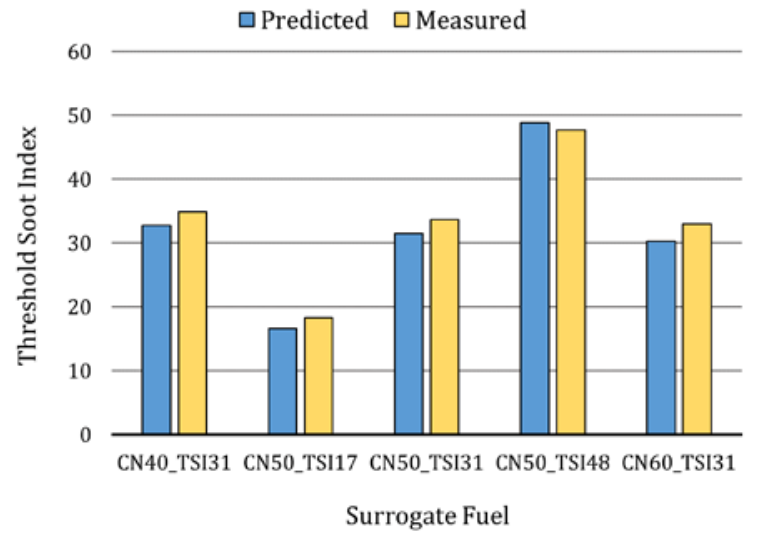

Figure 3. A comparison of predicted and measured TSI values for five surrogate fuels.

\subsection{2. $\quad$ Lower Heating Value}

The results for lower heating value are given in Figure 4. Relatively small changes in the LHV were observed as the blend ratios were adjusted to control cetane number and TSI. The measured LHV was consistently less than the predicted values. For the predicted values, the average LHV was $43.8 \mathrm{MJ} / \mathrm{kg}$ with 
a range of $0.9 \mathrm{MJ} / \mathrm{kg}$. For the measured values, the average was $42.7 \mathrm{MJ} / \mathrm{kg}$ with a range of $0.7 \mathrm{MJ} / \mathrm{kg}$. The 343 average difference between the predicted and measured LHV was $1.06 \mathrm{MJ} / \mathrm{kg}(2.5 \%)$ and the maximum 344 observed difference was $1.65 \mathrm{MJ} / \mathrm{kg}(3.8 \%)$.

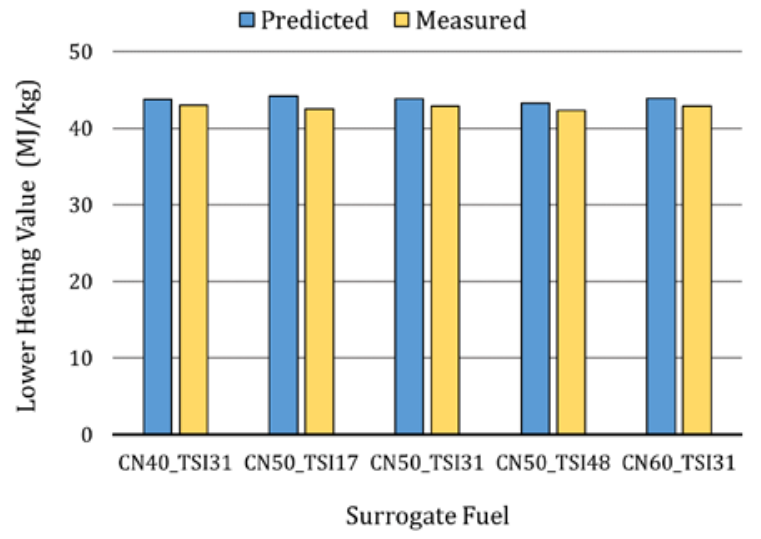

Figure 4. A comparison of predicted and measured LHV for five surrogate fuels.

\subsubsection{Kinematic Viscosity}

Figure 5 shows that adjusting the blend ratios to control cetane number and TSI value had little impact on the kinematic viscosity. The predicted values were slightly greater than the measured values. For these five surrogates, the predicted values averaged $2.71 \mathrm{cSt}$ while the measured values averaged 2.41; a difference of only $0.3 \mathrm{cSt}$. The maximum observed difference was $0.39 \mathrm{cSt}$. 


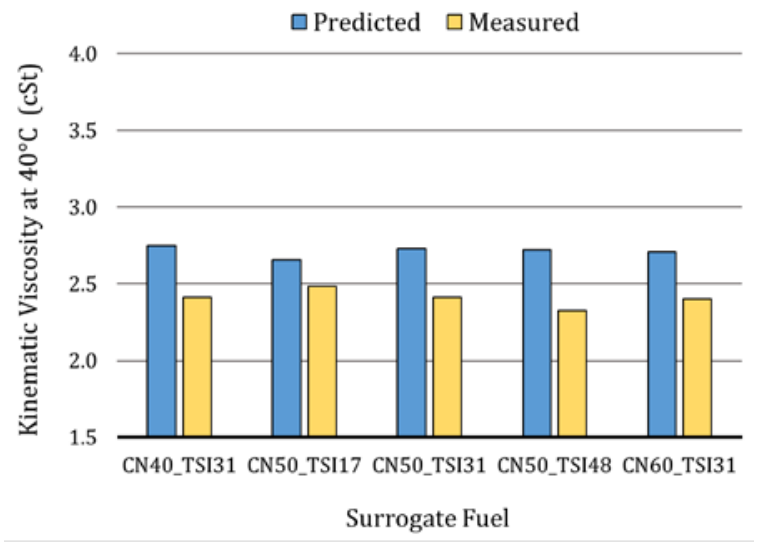

Figure 5. A comparison of predicted and measured kinematic viscosities for five surrogate fuels.

As shown in Figure 6, very close agreement was obtained between the predicted and measured values for density and molar H/C. For density, the predicted values for the five surrogate fuels ranged from 0.806 to $0.845 \mathrm{~g} / \mathrm{ml}$. The average difference between the predicted and measured denisty was only $0.003 \mathrm{~g} / \mathrm{ml}$ with a maximum difference of only $0.004 \mathrm{~g} / \mathrm{ml}$. The molar $\mathrm{H} / \mathrm{C}$ ranged from 1.693 to 2.016. The average difference between the predicted and measured values was only 0.003 and the maximum difference was 0.009 

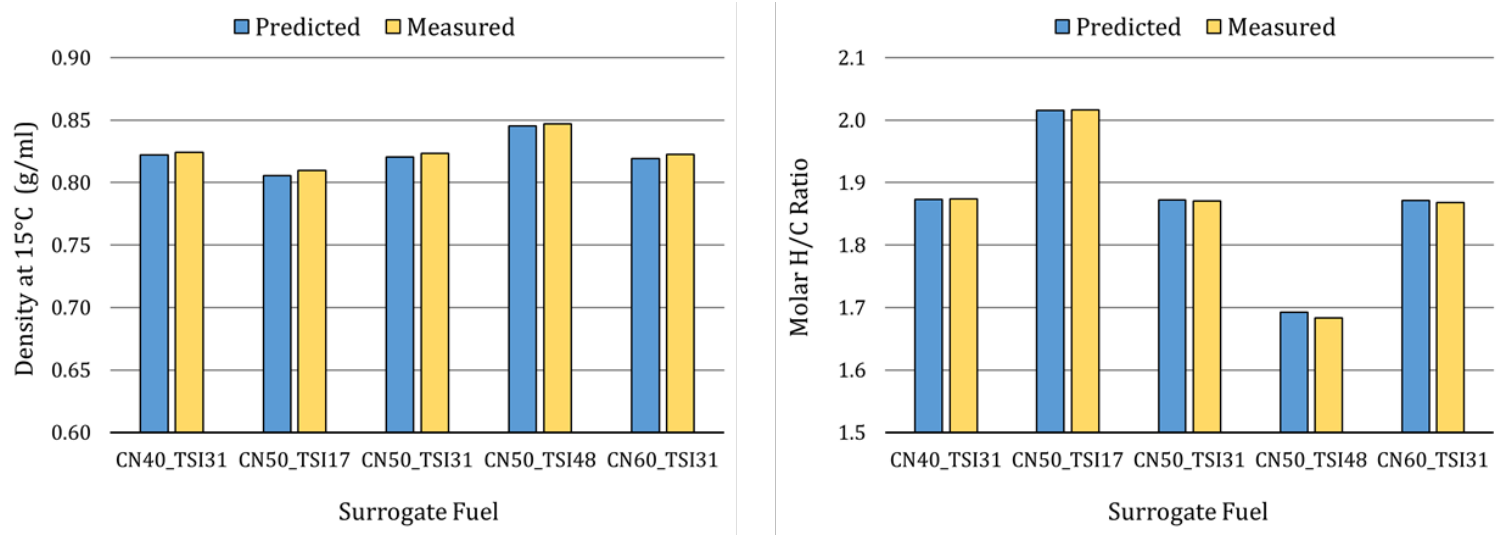

Figure 6. A comparison of predicted and measured density and molar $\mathrm{H} / \mathrm{C}$ values for five surrogate fuels.

\subsection{5. $\quad T_{10}$ and $T_{90}$ Distillation Temperatures}

The predicted surrogate fuel distillation curves were evaluated with the $\mathrm{T}_{10}$ and $\mathrm{T}_{90}$ distillation temperatures, see Figure 7. On average, the predicted temperatures for $\mathrm{T}_{10}$ were $8.6^{\circ} \mathrm{C}$ greater than the measured values. The maximum observed difference was $10^{\circ} \mathrm{C}$. A modestly increasing $\mathrm{T}_{10}$ trend was observed in surrogates CN50_TSI17, CN50_TSI31 and CN50_TSI48. This was due to a decrease in the decahydronaphthalene volume fraction and an increase in the 1-methylnaphthalene as the TSI value was raised from 17 to 48 . For these fuels, the predicted values for T90 were slightly greater than the measured values. On average, the predicted temperatures for $\mathrm{T}_{90}$ were $4.9^{\circ} \mathrm{C}$ higher than the measured values. The maximum observed difference between the predicted and measured $\mathrm{T}_{90}$ was $5.7^{\circ} \mathrm{C}$. 

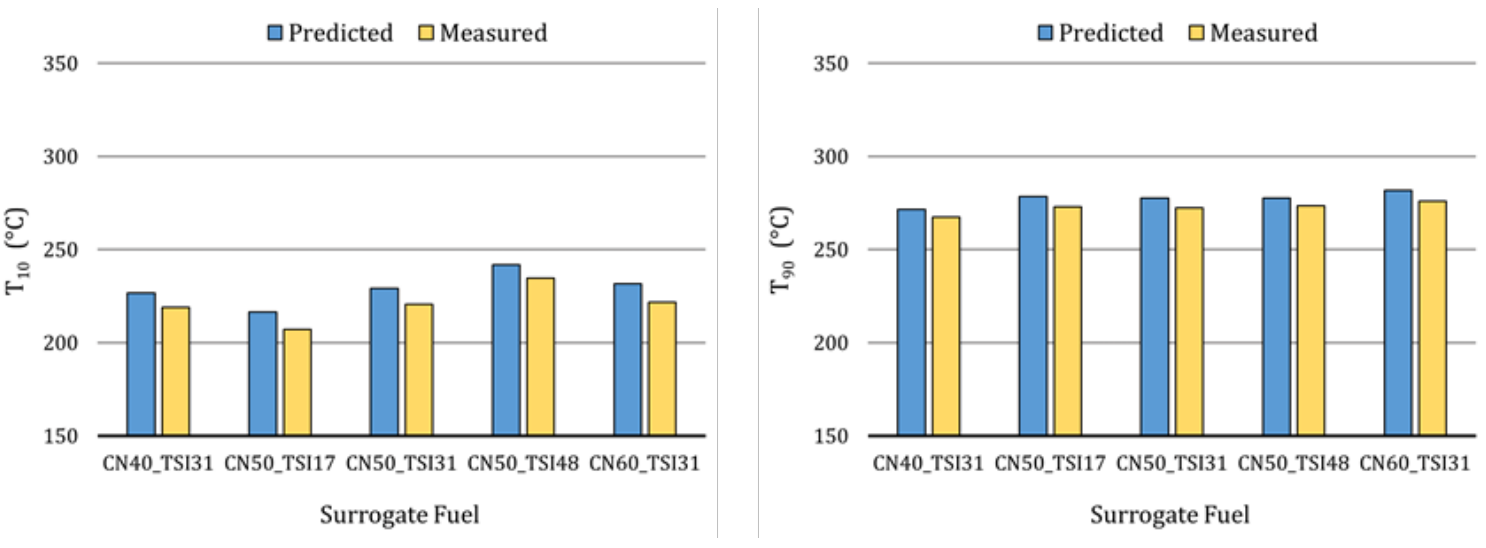

Figure 7. A comparison of predicted and measured $\mathrm{T}_{10}$ and $\mathrm{T}_{90}$ distillation temperatures for five surrogate fuels.

\subsection{Ignition Delay Evaluation}

The fuel cetane number provides a global indication of ignition quality. It is also necessary to understand the potential for the surrogate fuels to exhibit two-stage ignition, Negative Temperature Coefficient (NTC) and Zero Temperature Coefficient (ZTC) phenomenon [68]. In addition, the ignition behavior should respond as expected to blend formulations that control CN and TSI. To answer these questions, closedhomogeneous reactor simulations were conducted using the surrogate palette components and a set of five surrogate fuels. The fuels included CN50_TSI31 (baseline surrogate) coupled with CN40_TSI31 and CN60_TSI31 to explore the cetane number effect and the baseline surrogate coupled with fuels CN50_TSI17 and CN50_TSI48 to evaluate the impact of TSI with a constant CN.

Many of the reactor simulations demonstrated two-stage ignition, NTC and ZTC phenomenon. Regarding two-stage ignition, for this work the first-stage ignition was determined by the occurrence of the first hydroxyl radical $(\mathrm{OH})$ peak and the total ignition delay was established by the second $\mathrm{OH}$ peak (see Figure 8). Several pure fuel components and surrogate fuels exhibited the NTC or ZTC phenomenon. For NTC, 
increases in reactor initial temperature increased the ignition delay period as opposed to shortening the ignition delay. For ZTC, increased temperature had little impact on ignition delay.

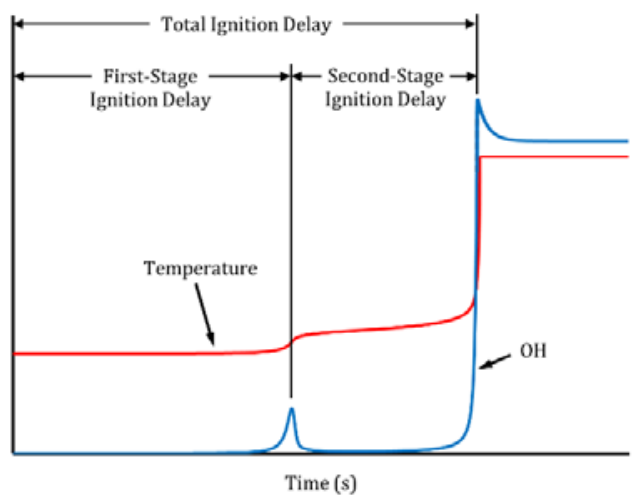

Figure 8. An example of a closed-homogeneous reactor simulation showing two-stage ignition delays identified by peak $\mathrm{OH}$ concentrations.

To comprehend the ignition characteristics of the surrogate fuel palette, Figure 9 shows the impact of temperature and hydrocarbon specie on the total ignition delay for reactor initial conditions of $\Phi=1.0$ and pressure $=50$ bar. Figure 9A contains n-alkanes and cyclo-aklanes while Figure 9B includes aromatics and iso-alkanes. The four hydrocarbon classes exhibited unique behaviors. The n-alkanes had the shortest ignition delays and the largest NTC regions. The cyclo-alkanes and iso-alkanes had longer ignition delays and smaller NTC regions or even ZTC regions. For theses hydrocarbons, the NTC/ZTC regions occurred at ignition delays greater than 1.0 ms. The aromatics had the longest ignition delays and did not exhibit NTC or ZTC behavior under these conditions. Compared to the other n-alkanes, n-hexadecane demonstrated a lesser NTC behavior that occurred over a broader temperature range. In fact, under these reactor conditions the n-hexadecane approached the ZTC phenomenon. Decahydronaphthalene exhibited NTC/ZTC in the 850-950K region while heptamethylnonane approached ZTC near 800-850K. 

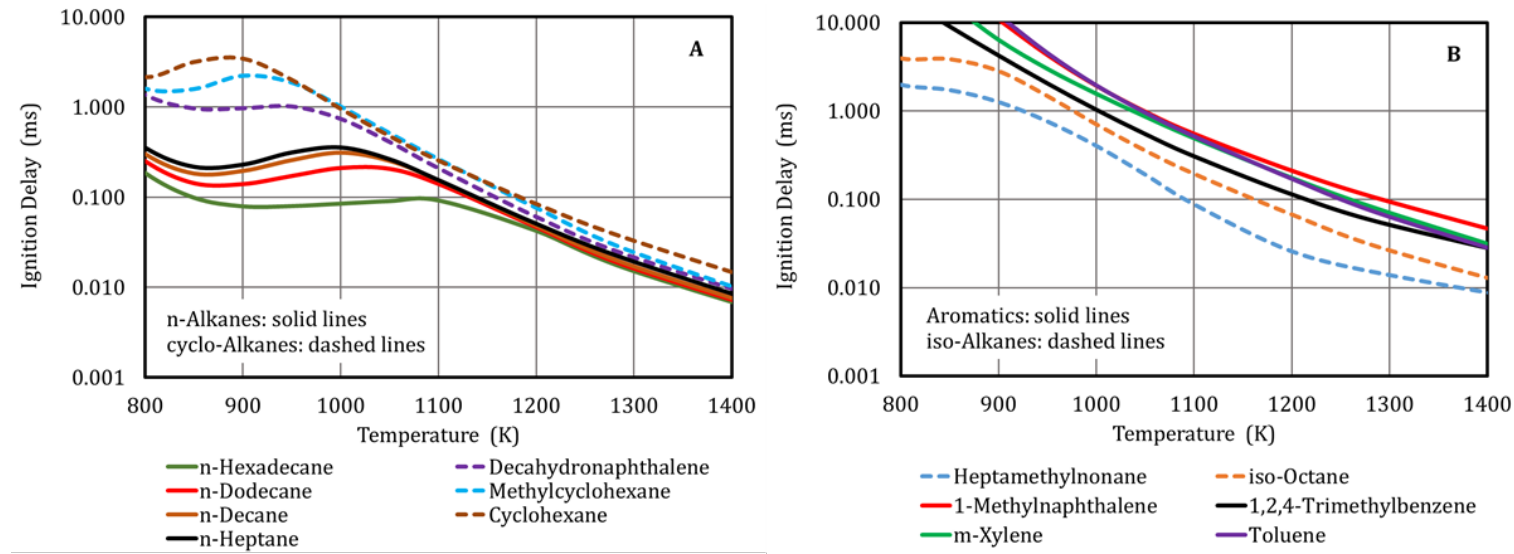

405

406

Figure 9. Results showing the total ignition delays for the surrogate palette components. Figure 9A contains n-alkanes and cyclo-alkanes and Figure 9B includes aromatics and iso-alkanes. Note the differences in ignition delay and NTC behavior between the hydrocarbon classes and within the classes. Closed-homogeneous reactor initial conditions: Temperature: 800-1400K, Equivalence Ratio = 1.0, Pressure $=50$ bar .

To examine the effects of fuel cetane number, Figure 10A shows the ignition delay results for three surrogate fuels having cetane numbers of 40,50 and 60 with the same TSI value of 31 . All of the fuels exhibited two-stage ignition and the ZTC behavior for reactor temperatures less than $\sim 1000 \mathrm{~K}$. The simulation results show that first-stage and total ignition delays were shortened as the fuel cetane number was increased from 40 to 60 . Increasing the cetane number also slightly increased the temperature range of the ZTC behavior. For these simulations, the ignition delay became independent of cetane number at reactor temperatures above $\sim 1050 \mathrm{~K}$. To investigate the effect of changing the fuel TSI at a constant cetane number, Figure 10B shows three surrogate fuels with a cetane number of 50 and TSI values of 17, 31 and 48. All three surrogate fuels had essentially the same first-stage and total ignition delays demonstrating that the changes in blend formulation to control TSI had little impact on the ignition delays. Recall that CN50_TSI17 does not contain 1-methylnaphthalene while CN50_TSI48 contains 0.27v/v 1- 
methylnaphthalene. The reactor simulations suggest that, depending on the reactor conditions, the surrogate fuels can exhibit two-stage ignition and NTC/ZTC behavior. The results also suggest the surrogate fuels provide independent control of fuel cetane number and threshold soot index.

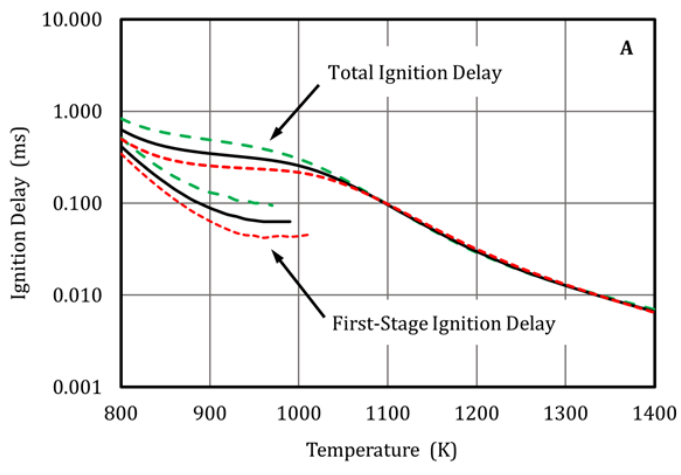

- -CN40_TSI31 —CN50_TSI31 ---CN60_TSI31

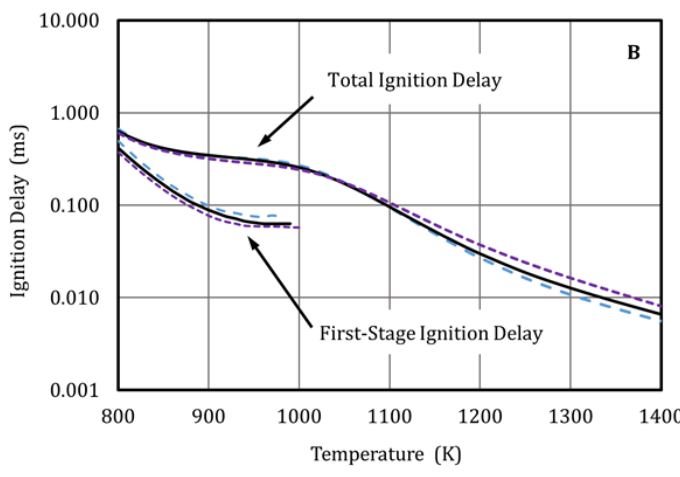

- -CN50_TSI17 —CN50_TSI31 ---CN50_TSI48

Figure 10. Results showing the first-stage and total ignition delays for five surrogate fuels. Figure 10A includes three surrogate fuels with cetane numbers of 40,50 and 60 and with TSI=31. Figure 10B contains three surrogate fuels with cetane number=50 and TSI values of 17, 31 and 48. Closed-homogeneous reactor initial conditions: Temperature: 800-1400K, Equivalence Ratio $=1.0$, Pressure $=50$ bar.

\subsection{Market Fuel Comparison}

To ensure the Surrogate Fuel Library was representative of real-world fuels, the predicted properties were compared to the five market fuels shown in Table 2. In the figures below, the chart on the left shows the predicted values for the surrogates. The surrogates are grouped by their TSI values and sorted in the order of increasing cetane number. The chart on the right shows the measured values for the market fuels.

\subsubsection{Density}

Results for density are shown in Figure 11. For a given TSI value the surrogate densities were reasonably steady. Since $n$-hexadecane and heptamethylnonane have the same density, manipulating their volume fractions to control cetane number did not impact the density of the surrogate fuels. The surrogate fuel 
densities increased by about $5 \%$ as the TSI value was increased from 17 to 48 due to increased amounts of 1-methylnaphthalene. The surrogate fuel densities ranged from 0.802 to $0.845 \mathrm{~g} / \mathrm{ml}$ and were mostly within the range spanned by the market Diesel fuels.

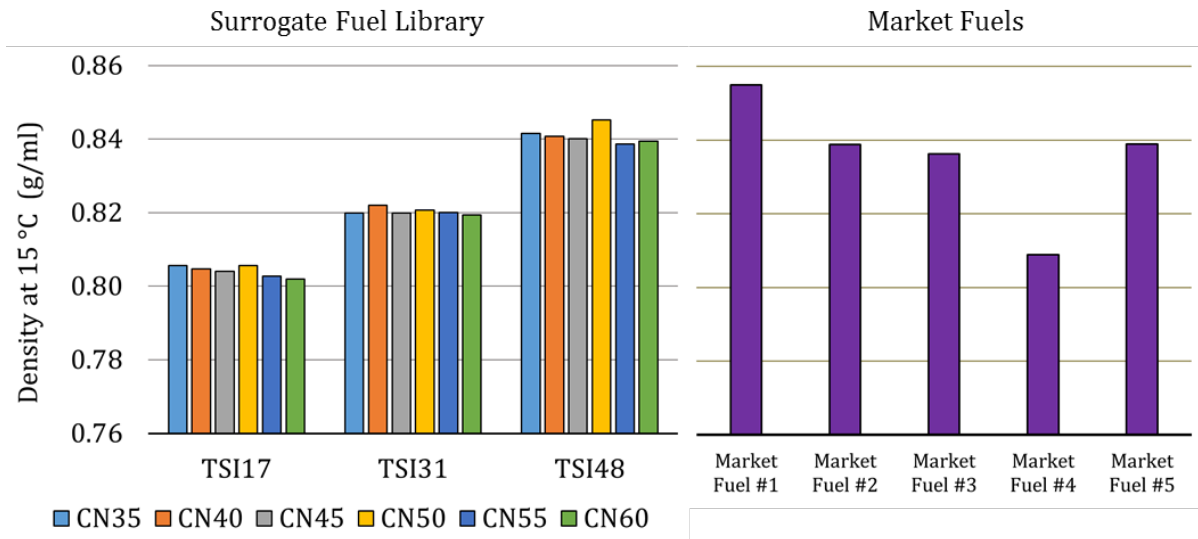

Figure 11. Surrogate fuel predicted densities compared to the measured densities from the market fuels.

\subsubsection{Kinematic Viscosity}

Figure 12 provides the results for kinematic viscosity. For the Surrogate Fuel Library, adjusting the blend ratios to control cetane number and TSI had very little impact on the kinematic viscosity. As cetane number varied from 35 to 60 the viscosity decreased by about $0.05 \mathrm{cSt}$. Increasing the TSI from 17 to 48 increased viscosity by about 0.05 cSt. For the surrogate fuels, the average kinematic viscosity was $2.73 \mathrm{cSt}$ while the market fuels averaged $2.41 \mathrm{cSt}$. The viscosities of the surrogate fuels were within the range of the market fuels and the requirements established in ASTM D975 [41]. 


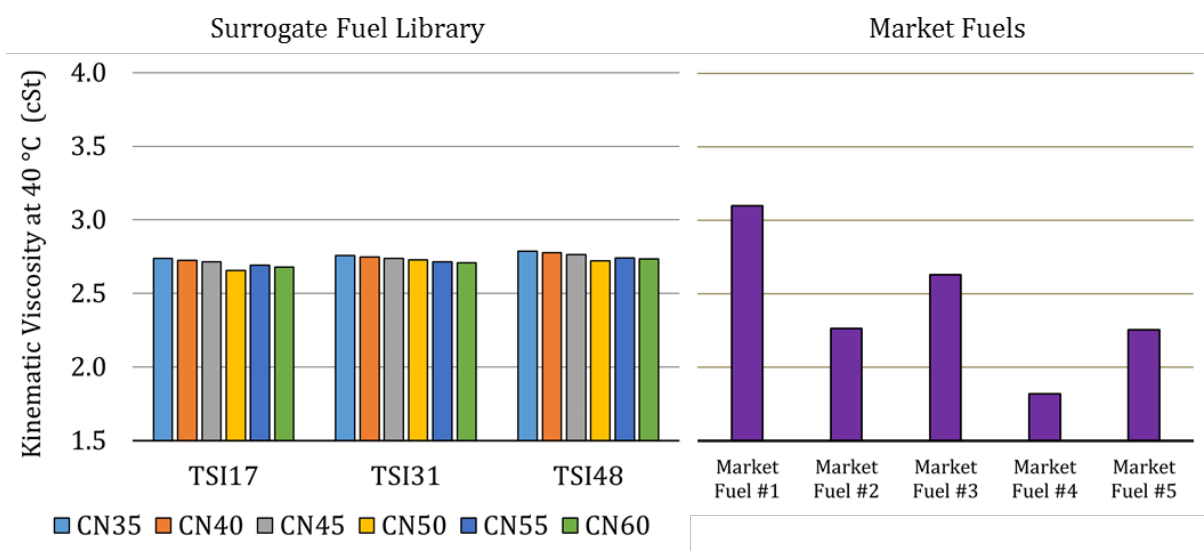

452

453

454

Figure 12. Surrogate fuel predicted viscosities compared to the measured viscosities from the market fuels.

\subsubsection{Energy Density}

The energy density $(\mathrm{kJ} / \mathrm{ml})$ was calculated by multiplying the fuel density and heating values. The results are given in Figure 13. For the surrogate fuels, the energy density was not influenced by changes in cetane number and increased modestly as TSI increased from 17 to 48 . The values for the surrogate fuels spanned about the same range as the market fuels. The average for the surrogate fuels was $35.97 \mathrm{~kJ} / \mathrm{ml}$ compared to an average of $36.06 \mathrm{~kJ} / \mathrm{ml}$ for the market fuels. 


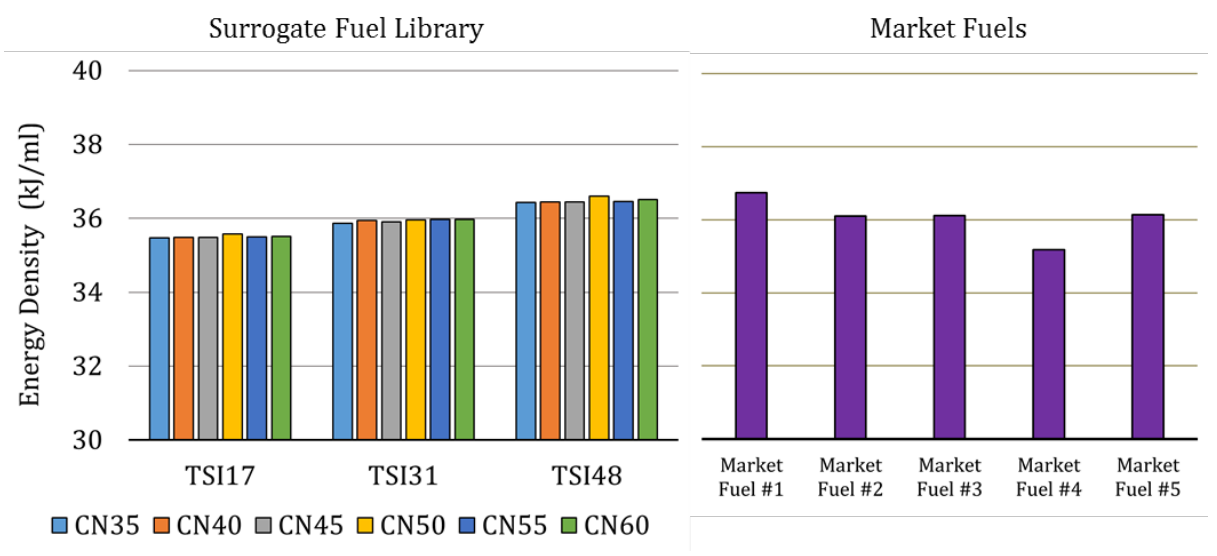

460

461

462

463

464

465

466

467

Figure 13. Surrogate fuel predicted energy densities compared to the measured energy densities from the market fuels.

\subsubsection{Distillation Temperatures}

The $\mathrm{T}_{10}$ distillation temperature results are shown in Figure 14. For a given TSI value increasing the cetane number from 35 to 60 increased the $\mathrm{T}_{10}$ distillation temperature by about $10^{\circ} \mathrm{C}$. For a given cetane number, increasing the TSI from 17 to 48 raised the $\mathrm{T}_{10}$ distillation temperature by around $25^{\circ} \mathrm{C}$. For all of the surrogates, $\mathrm{T}_{10}$ averaged $230^{\circ} \mathrm{C}$ compared to an average of $203^{\circ} \mathrm{C}$ for the market fuels. The $\mathrm{T}_{10}$ range for the surrogates was $33^{\circ} \mathrm{C}$ compared to $40^{\circ} \mathrm{C}$ for the market fuels. 


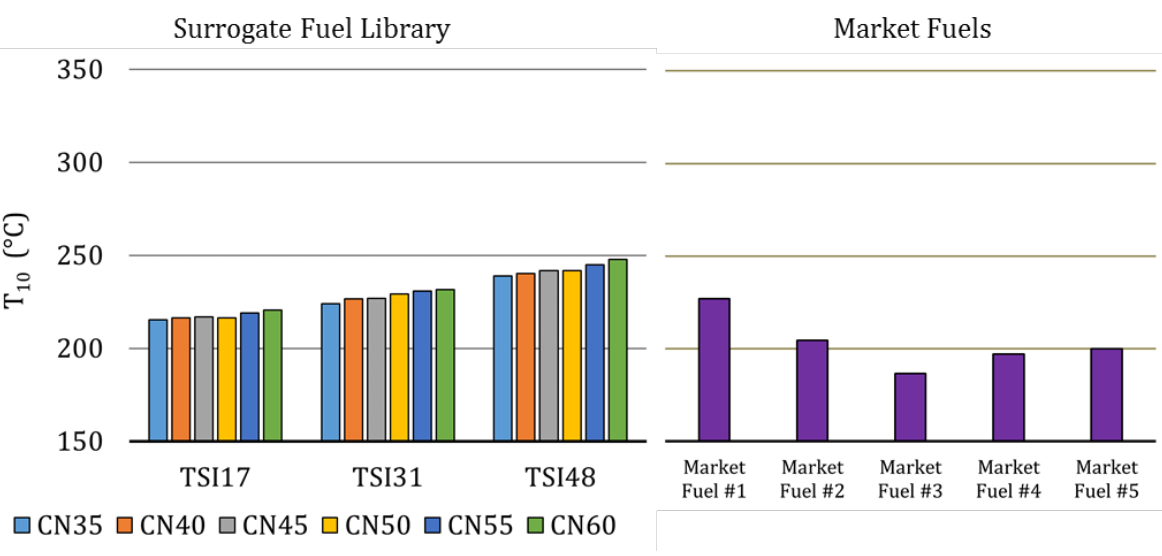

469

470

471

472

473

474

475

Figure 14. Surrogate fuel predicted $\mathrm{T}_{10}$ distillation temperatures compared to the measured $\mathrm{T}_{10}$ distillation temperatures from the market fuels.

Figure 15 shows the $T_{90}$ distillation temperature results. For a given TSI value, increasing the cetane number from 35 to 60 raised the $\mathrm{T}_{90}$ by about $17^{\circ} \mathrm{C}$. In general, at a given cetane number the $\mathrm{T}_{90}$ was not affected by surrogate blend changes to control TSI. The $\mathrm{T}_{90}$ averaged $275^{\circ} \mathrm{C}$ for the surrogate fuels compared to an average of $305^{\circ} \mathrm{C}$ for the market fuels. The market fuels had a T90 range of $57^{\circ} \mathrm{C}$ compared to only $20^{\circ} \mathrm{C}$ for the surrogate fuels. 


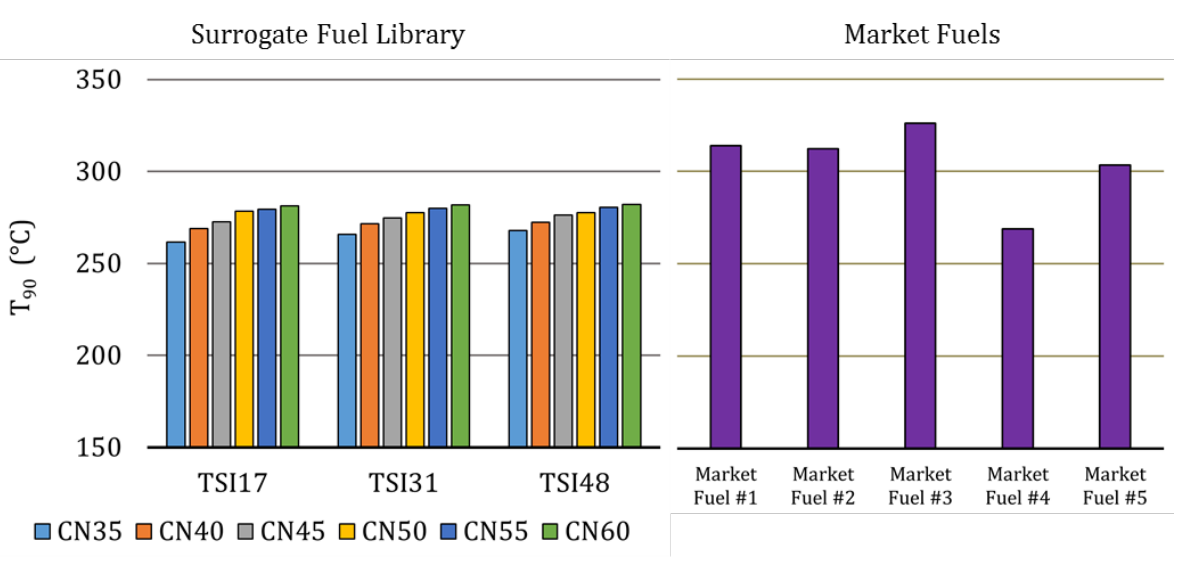

Figure 15. Surrogate fuel predicted $\mathrm{T}_{90}$ distillation temperatures compared to the measured $\mathrm{T}_{90}$ distillation temperatures from the market fuels.

\section{Summary and Conclusions}

The objective of this work was to provide fully representative multi-component surrogate Diesel fuels that, along with their chemical kinetic mechanisms, can be brought to routine use in applied research, industrial applications, and most importantly, the engine designer's toolkit. The results are summarized as follows:

- A process was developed that coupled the Reaction Workbench - Surrogate Blend Optimizer (SBO) with blending rules established by this work to create a Diesel Surrogate Fuel Library.

- A surrogate fuel palette consisting of 13 hydrocarbon species was selected from the 55 available species within the ANSYS Model Fuel Library. From this palette, the surrogate fuel objectives and requirements were achieved with four components: n-hexadecane, 2,2,4,4,6,8,8heptamethylnonane, decahydronaphthalene and 1-methylnaphthalene.

- The combustion, physical and chemical properties of the baseline Diesel fuel (a market fuel) were accurately matched by the baseline surrogate fuel. 
- The SBO fuel property predictions were validated. A set of five surrogate fuels that spanned a cetane range from 40 to 60 and a TSI range from 17 to 48 were blended and tested. Good agreement was obtained between the SBO predicted and the ASTM measured fuel properties.

- The Surrogate Fuel Library was validated. A comparison of the 18 surrogate fuels with five market Diesel fuels showed good agreement for density, kinematic viscosity, energy density $(\mathrm{kJ} / \mathrm{ml})$, and the $\mathrm{T}_{10}$ and $\mathrm{T}_{90}$ distillation temperatures.

- To support future Diesel spray, combustion and emission investigations, the densities, viscosities, surface tensions and lower heating values of the surrogate fuels were in close agreement with fullrange petroleum Diesel fuels.

- The library provides a broad range of fuel cetane numbers to quantify the impact of this key property on new combustion technologies and a wide range of fuel sooting tendency useful for the improvement and validation of models to predict soot and exhaust particles.

\section{Acknowledgements}

The authors would like to thank General Motors Global Research and Development for supporting this research. Additionally, the authors thank Dr. Venkatesh Gopalakrishnan and Dr. Seunghwan Keum for many useful discussions throughout this investigation.

\section{References}

[1] Jacobs, T., Knafl, A., Bohac, S., Assanis, D. and Szymkowicz, P., "The Development of Throttled and Unthrottled PCI Combustion in a Light-Duty Diesel Engine", SAE Technical Paper Series, 2006, doi:10.4271/2006-01-0202. 
[2] Di Blasio, G., Beatrice, C. and Molina, S., "Effect of Port Injected Ethanol on Combustion Characteristics in a Dual-Fuel Light Duty Diesel Engine", SAE Technical Paper Series, 2013, doi:10.4271/2013-011692.

[3] Beatrice, C., Avolio, G., Del Giacomo, N. and Guido, C., "Compression Ratio Influence on the Performance of an Advanced Single-Cylinder Diesel Engine Operating in Conventional and Low Temperature Combustion Mode", SAE Technical Paper Series, 2008, doi:10.4271/2008-01-1678.

[4] Kokjohn, S., Hanson, R., Splitter, D. and Reitz, R., "Fuel Reactivity Controlled Compression Ignition (RCCI): A Pathway to Controlled High-Efficiency Clean Combustion", International Journal of Engine Research 12(3):209-226, 2011, doi:10.1177/1468087411401548.

[5] Benajes, J., García, A., Monsalve-Serrano, J. and Boronat, V., "Achieving Clean and Efficient Engine Operation up to Full Load by Combining Optimized RCCI and Dual-Duel Diesel-Gasoline Combustion Strategies", Energy Conversion and Management 136:142-151, 2017, doi:10.1016/j.enconman.2017.01.010.

[6] Chevron, "Diesel Fuels Technical Review", Chevron Products Company, http://www.chevron.com/products/prodserv/fuels/bulletin/diesel, 2007.

[7] Vendeuvre, C., Ruiz-Guerrero, R., Bertoncini, F., Duval, L., Thiébaut, D. and Hennion, M., "Characterisation of Middle-Distillates by Comprehensive Two-Dimensional Gas Chromatography (GC×GC): A Powerful Alternative for Performing Various Standard Analysis of Middle-Distillates", Journal of Chromatography A 1086(1-2):21-28, 2005, doi:10.1016/j.chroma.2005.05.106.

[8] Farrell, J., Cernansky, N., Dryer, F., Law, C., Friend, D., Hergart, C., McDavid, R., Patel, A., Mueller, C. and Pitsch, H., "Development of an Experimental Database and Kinetic Models for Surrogate Diesel Fuels", SAE Technical Paper Series, 2007, doi:10.4271/2007-01-0201. 
[9] Mueller, C., Cannella, W., Bruno, T., Bunting, B., Dettman, H., Franz, J., Huber, M., Natarajan, M., Pitz, W., Ratcliff, M. and Wright, K., "Methodology for Formulating Diesel Surrogate Fuels with Accurate Compositional, Ignition-Quality, and Volatility Characteristics", Energy and Fuels 26(6):3284-3303, 2012, doi:10.1021/ef300303e.

[10] Ahmedi, A., Ahmed, S. and Kalghatgi, G., "Simulating Combustion in a PCI (Premixed Compression Ignition) Engine using DI-SRM and 3 Components Surrogate Model", Combustion and Flame 162(10):3728-3739, 2015, doi:10.1016/j.combustflame.2015.07.011.

[11] Anand, K., Ra, Y., Reitz, R. and Bunting, B., "Surrogate Model Development for Fuels for Advanced Combustion Engines", Energy and Fuels 25(4):1474-1484, 2011, doi:10.1021/ef101719a.

[12] Ciajolo, A., D'Anna, A., Barbella, R. and Bertoli, C., "Combustion of Tetradecane and Tetradecane/ $\alpha-$ Methylnaphthalene in a Diesel Engine with Regard to Soot and PAH Formation", Combustion Science and Technology 87(1-6):127-137, 1993, doi:10.1080/00102209208947211.

[13] Diez, A., Crookes, R. and Lovas, T., "Experimental Studies of Autoignition and Soot Formation of Diesel Surrogate Fuels", Proceedings of The Institution of Mechanical Engineers, Part D: Journal of Automobile Engineering 227(5):656-664, 2012, doi:10.1177/0954407012458402.

[14] Hakka, M., Glaude, P., Herbinet, O. and Battin-Leclerc, F., "Experimental Study of the Oxidation of Large Surrogates for Diesel and Biodiesel Fuels", Combustion and Flame 156(11):2129-2144, 2009, doi:10.1016/j.combustflame.2009.06.003.

[15] Kalghatgi, G., Hildingsson, L., Harrison, A. and Johansson, B., "Surrogate Fuels for Premixed Combustion in Compression Ignition Engines", International Journal of Engine Research 12(5):452465, 2011, doi:10.1177/1468087411409307. 
[16] Luo, J., Yao, M., Liu, H. and Yang, B., "Experimental and Numerical Study on Suitable Diesel Fuel Surrogates in Low Temperature Combustion Conditions", Fuel 97:621-629, 2012, doi:10.1016/j.fuel.2012.02.057.

[17] Payri, R., Viera, J., Gopalakrishnan, V. and Szymkowicz, P., "The Effect of Nozzle Geometry over the Evaporative Spray Formation for Three Different Fuels", Fuel 188:645-660, 2017, doi:10.1016/j.fuel.2016.10.064.

[18] Pitz, W., Westbrook, C., Herbinet, O. and Silke, E., "Progress in Chemical Kinetic Modeling for Surrogate Fuels", 7th International Conference on Modeling and Diagnostics for Advanced Engine Systems, COMODIA 2008, Sapporo, Japan: Pages 9-15, 2008.

[19] Ra, Y., Reitz, R., McFarlane, J. and Daw, C., "Effects of Fuel Physical Properties on Diesel Engine Combustion using Diesel and Bio-diesel Fuels", SAE International Journal of Fuels and Lubricants 1(1):703-718, 2008, doi:10.4271/2008-01-1379.

[20] Hernandez, J., Sanz-Argent, J., Benajes, J. and Molina, S., "Selection of a Diesel Fuel Surrogate for the Prediction of Auto-Ignition under HCCI Engine Conditions", Fuel 87(6):655-665, 2008, doi:10.1016/j.fuel.2007.05.019.

[21] Lindstedt, R. and Maurice, L., "Detailed Kinetic Modelling of n-Heptane Combustion", Combustion Science and Technology 107(4-6):317-353, 1995, doi:10.1080/00102209508907810.

[22] Curran, H., Gaffuri, P., Pitz, W. and Westbrook, C., "A Comprehensive Modeling Study of n-Heptane Oxidation", Combustion and Flame 114(1-2):149-177, 1998, doi:10.1016/s0010-2180(97)00282-4.

[23] Tao, F., Reitz, R. and Foster, D., "Revisit of Diesel Reference Fuel (n-Heptane) Mechanism Applied to Multidimensional Diesel Ignition and Combustion Simulations", Seventeenth International Multidimensional Engine Modeling User's Group Meeting, 2007. 
[24] Desantes, J., Lopez, J., Garcia, J. and Pastor, J., "Evaporative Diesel Spray Modeling", Atomization and Sprays 17(3):193-231, 2007, doi:10.1615/atomizspr.v17.i3.10.

[25] Bardi, M., Payri, R., Malbec, L., Bruneaux, G., Pickett, L., Manin, J., Bazyn, T. and Genzale, C., "Engine Combustion Network: Comparison of Spray Development, Vaporization, and Combustion in Different Combustion Vessels", Atomization and Sprays 22(10):807-842, 2012, doi:10.1615/atomizspr.2013005837.

[26] Payri R., Salvador F.J., Gimeno J., Peraza J.E., “Experimental Study of the Injection Conditions Influence over n-Dodecane and Diesel Sprays with Two ECN Single-Hole Nozzles. Part II: Reactive Atmosphere", Energy Conversion and Management 126:1157-1167, 2016, doi: 10.1016/j.enconman.2016.07.079.

[27] Pitz, W., Westbrook, C., Herbinet, O. and Silke, E., "Progress in Chemical Kinetic Modeling for Surrogate Fuels", 7th International Conference on Modeling and Diagnostics for Advanced Engine Systems, COMODIA 2008, Sapporo, Japan: Pages 9-15, 2008.

[28] Hakka, M., Glaude, P., Herbinet, O. and Battin-Leclerc, F., "Experimental Study of the Oxidation of Large Surrogates for Diesel and Biodiesel Fuels", Combustion and Flame 156(11):2129-2144, 2009, doi:10.1016/j.combustflame.2009.06.003.

[29] Westbrook, C., Pitz, W., Herbinet, O., Curran, H. and Silke, E., "A Comprehensive Detailed Chemical Kinetic Reaction Mechanism for Combustion of n-Alkane Hydrocarbons from n-Octane to nHexadecane", $\quad$ Combustion and $\quad$ Flame 156(1):181-199, 2009, doi:10.1016/j.combustflame.2008.07.014/

[30] Pitz, W. and Mueller, C., "Recent Progress in the Development of Diesel Surrogate Fuels", Progress in Energy and Combustion Science 37(3):330-350, 2011, doi:10.1016/j.pecs.2010.06.004. 
[31] ANSYS, "The Model Fuels Library: Accurate Combustion Chemistry for the Real World", ANSYS, Inc., 2016. http://www.ansys.com/-/media/Ansys/corporate/resourcelibrary/brochure/ansys-modelfuel-library-brochure.pdf, 2017.

[32] Weber J., Won H.W., Peters N., "Experimental Validation of a Surrogate Fuel for Diesel”, SAE Technical Paper Series, 2007, doi:10.4271/2007-01-1842.

[33] Natelson R., Kurman M., Cernansky N., Miller D., “Experimental Investigation of Surrogates for Jet and Diesel Fuels", Fuel 87(10-11)2339-2342, 2008, doi:10.1016/j.fuel.2007.11.009.

[34] Kalghatgi, G., Hildingsson, L., Harrison, A. and Johansson, B., "Surrogate Fuels for Premixed Combustion in Compression Ignition Engines", International Journal of Engine Research 12(5):452465, 2011, doi:10.1177/1468087411409307.

[35] Luo, J., Yao, M., Liu, H. and Yang, B., "Experimental and Numerical Study on Suitable Diesel Fuel Surrogates in Low Temperature Combustion Conditions", Fuel 97:621-629, 2012, doi:10.1016/j.fuel.2012.02.057.

[36] Poon H.M., Pang K.M., Ng H.K., Gan S., Schramm J., "Development of Multi-Component Diesel Surrogate Fuel Models - Part I: Validation of Reduced Mechanisms of Diesel Fuel Constituents in 0-D Kinetic Simulations", Fuel 180:433-441, 2016, doi:10.1016/j.fuel.2016.04.043.

[37] Poon H.M., Pang K.M., Ng H.K., Gan S., Schramm J., "Development of Multi-Component Diesel Surrogate Fuel Models - Part II: Validation of the Integrated Mechanisms in 0-D Kinetic and 2-D CFD Spray Combustion Simulations", Fuel 181:120-130, 2016, doi:10.1016/j.fuel.2016.04.114.

[38] Mueller C., Cannella W., Bays J., Bruno T., Defabio K., Dettman H., Gieleciak R., Huber M., Kweon C.-B., McConnell S., Pitz W., Ratcliff M., "Diesel Surrogate Fuels for Engine Testing and Chemical-Kinetic 
Modeling: Compositions and Properties", Energy and Fuels, 30:1445-1461, 2016, doi:10.1021/acs.energyfuels.5b02879.

[39] Liu X., Wang H., Wang X., Zheng Z., Yao M., "Experimental and Modelling Investigations of the Diesel Surrogate Fuels in Direct Injection Compression Ignition Combustion", Applied Energy 189:187-200, 2017, doi:10.1016/j.apenergy.2016.12.054.

[40] Naik C.V., Puduppakkam K., Meeks E., "Simulation and Analysis of In-Cylinder Soot Formation in a Low Temperature Combustion Diesel Engine Using a Detailed Reaction Mechanism", SAE International Journal of Engines 6(2):2013 doi:10.4271/2013-01-1565.

[41] ASTM International, "Specification for Diesel Fuel Oils", ASTM International, ASTM D 975-16a, 2016, doi:10.1520/d0975-16a.

[42] European Committee for Standardization (CEN), "Automotive fuels - Diesel - Requirements and test methods", European Committee for Standardization, EN 590:2009: E, 2009.

[43] Szymkowicz, P., 2017, "Analytical and Experimental Investigation of Multi-Component Surrogate Diesel Fuels", Ph.D. Dissertation, Universitat Politecnica De Valencia.

[44] Yang, H., Shuai, S., Wang, Z., Wang, J. and Xu, H., "New Premixed Compression Ignition Concept for Direct Injection IC Engines Fueled with Straight-Run Naphtha", Energy Conversion and Management 68:161-168, 2013, doi:10.1016/j.enconman.2013.01.006.

[45] Chang, J., Kalghatgi, G., Amer, A., Adomeit, P., Rohs, H. and Heuser, B., "Vehicle Demonstration of Naphtha Fuel Achieving Both High Efficiency and Drivability with EUR06 Engine-Out NOx Emission", SAE International Journal of Engines 6(1):101-119, 2013, doi:10.4271/2013-01-0267. 
[46] Abu-Jrai, A., Rodríguez-Fernández, J., Tsolakis, A., Megaritis, A., Theinnoi, K., Cracknell, R. and Clark, R., "Performance, Combustion and Emissions of a Diesel Engine Operated with Reformed EGR. Comparison of Diesel and GTL Fuelling", Fuel 88(6):1031-1041, 2009, doi:10.1016/j.fuel.2008.12.001.

[47] Labeckas, G. and Slavinskas, S., "Performance and Emission Characteristics of a Direct Injection Diesel Engine Operating on KDV Synthetic Diesel Fuel", Energy Conversion and Management 66:173-188, 2013, doi:10.1016/j.enconman.2012.10.004.

[48] ANSYS Model Fuel Library, ANSYS Reaction Design: San Diego, 2015.

[49] Kim D., Martz J., Abdul-Nour A., Yu X., Jansons M., Violi A., "A Six-Component Surrogate for Emulating the Physical and Chemical Characteristics of Conventional and Alternative Jet Fuels and their Blends", Combustion and Flame 179:86-94, 2017, doi:10.1016/j.combustflame.2017.01.025.

[50] Chen X., Khani E., Chen C.P., "A Unified Jet Fuel Surrogate for Droplet Evaporation and Ignition”, Fuel 182:284-291, 2016, doi: 10.1016/j.fuel.2016.05.114.

[51] Ahmed A., Goteng G., Shankar V.S.B., Al-Qurashi K., Roberts W.L., Sarathy S.M., "A Computational Methodology for Formulating Gasoline Surrogate Fuels with Accurate Physical and Chemical Kinetic Properties", Fuel 143:290-300, 2015, doi: 10.1016/j.fuel.2014.11.022.

[52] Reiter A., Wallek T., Pfennig A., Zeymer M., "Surrogate Generation and Evaluation for Diesel Fuel", Energy and Fuels 29:4181-4192, 2015, doi:10.1021/acs.energyfuels.5b00422.

[53] Su X., Ra Y., Reitz R., "A Surrogate Fuel Formulation Approach for Real Transportation Fuels with Application to Multi-Dimensional Engine Simulations", SAE International Journal of Fuels and Lubricants 7(1), 2014, doi:10.4271/2014-01-1464. 
[54] Windom B.C., Huber M.L., Bruno T.J., Lown A.L., Lira C.T., "Measurements and Modeling Study on a High-Aromatic Diesel Fuel", Energy and Fuels 26:1787-1797, 2012, doi:10.1021/ef201861b.

[55] Liang, L., Naik, C., Puduppakkam, K., Wang, C., Modak, A., Meeks, E., Ge, H., Reitz, R. and Rutland, C., "Efficient Simulation of Diesel Engine Combustion Using Realistic Chemical Kinetics in CFD", SAE Technical Paper Series, 2010, doi:10.4271/2010-01-0178.

[56] Naik, C., Puduppakkam, K., Wang, C., Kottalam, J., Liang, L., Hodgson, D. and Meeks, E., "Applying Detailed Kinetics to Realistic Engine Simulation: the Surrogate Blend Optimizer and Mechanism Reduction Strategies", SAE International Journal of Engines 3(1):241-259, 2010, doi:10.4271/201001-0541.

[57] Dooley, S., Won, S., Chaos, M., Heyne, J., Ju, Y., Dryer, F., Kumar, K., Sung, C., Wang, H., Oehlschlaeger, M., Santoro, R. and Litzinger, T., "A Jet Fuel Surrogate Formulated by Real Fuel Properties", Combustion and Flame 157(12):2333-2339, 2010, doi:10.1016/j.combustflame.2010.07.001.

[58] Androulakis I., Weisel M., Hsu C., Qian K., Green L., Farrell J., Nakakita K., “An Integrated Approach for Creating Model Diesel Fuels", Energy and Fuels 19:111-119, 2005, doi:10.1021/ef0498925.

[59] ANSYS Chemkin Reaction Workbench 17.0 (15151), ANSYS Reaction Design: San Diego, 2016.

[60] Calcote, H. and Manos, D., "Effect of Molecular Structure on Incipient Soot Formation", Combustion and Flame 49(1-3):289-304, 1983, doi:10.1016/0010-2180(83)90172-4.

[61] ASTM International, "Test Method for Determination of Ignition Delay and Derived Cetane Number (DCN) of Diesel Fuel Oils by Combustion in a Constant Volume Chamber", ASTM International, ASTM D 6890, May 2017, doi:10.1520/d6890-13b. 
[62] ASTM International, "Test Method for Smoke Point of Kerosine and Aviation Turbine Fuel", ASTM International, ASTM D 1322-12, May 2017, doi:10.1520/d1322-12.

[63] ASTM International, "Standard Test Method for Heat of Combustion of Liquid Hydrocarbon Fuels by Bomb Calorimeter", ASTM International, ASTM D 240-09, 2009.

[64] ASTM International, "Test Method for Density, Relative Density, and API Gravity of Liquids by Digital Density Meter", ASTM International, ASTM D 4052-11, 2011, doi:10.1520/d4052-11.

[65] Wang, F., Wu, J. and Liu, Z., "Surface Tensions of Mixtures of Diesel Oil or Gasoline and Dimethoxymethane, Dimethyl Carbonate, or Ethanol", Energy and Fuels 20(6):2471-2474, 2006, doi:10.1021/ef060231c.

[66] Ra, Y., Reitz, R., McFarlane, J. and Daw, C., "Effects of Fuel Physical Properties on Diesel Engine Combustion using Diesel and Bio-diesel Fuels", SAE International Journal of Fuels And Lubricants 1(1):703-718, 2008, doi:10.4271/2008-01-1379.

[67] Design Institute for Physical Properties, "AIChE DIPPR Project 801 - Full Version", KNovel Corporation, (2005; 2008-2012; 2016)", Http://App.Knovel.Com/Hotlink/Toc/Id:Kpdipprpf7/Dippr-Project-801-Full/Dippr-Project-801Full, 2016.

[68] Fu X., Aggarwal S.K., "Two-Stage Ignition and NTC Phenomenon in Diesel Engines”, Fuel 144:188-196, 2015, doi:10.1016/j.fuel.2014.12.059. 
701 Table A1. Blend volume fractions, mass fractions, and predicted fuel properties for six surrogate fuels with 702 cetane numbers ranging from 35 to 60 (in increments of 5) and a TSI value of 17.

\begin{tabular}{|c|c|c|c|c|c|c|}
\hline Predicted Fuel Property & $\begin{array}{l}\text { CN35 } \\
\text { TSI17 }\end{array}$ & $\begin{array}{l}\text { CN40_- } \\
\text { TSI17 }\end{array}$ & $\begin{array}{l}\text { CN45 } \\
\text { TSI17 }\end{array}$ & $\begin{array}{l}\text { CN50_- } \\
\text { TSI17 }\end{array}$ & $\begin{array}{l}\text { CN55 } \\
\text { TSI17 }\end{array}$ & $\begin{array}{l}\text { CN60_ } \\
\text { TSI17 }\end{array}$ \\
\hline n-Hexadecane (v/v) & 0.13 & 0.20 & 0.25 & 0.34 & 0.37 & 0.43 \\
\hline Heptamethylnonane (v/v) & 0.57 & 0.50 & 0.45 & 0.33 & 0.33 & 0.27 \\
\hline Decahydronaphthalene (v/v) & 0.30 & 0.30 & 0.30 & 0.33 & 0.30 & 0.30 \\
\hline 1-Methylnaphthalene $(\mathrm{v} / \mathrm{v})$ & 0.00 & 0.00 & 0.00 & 0.00 & 0.00 & 0.00 \\
\hline n-Hexadecane $(\mathrm{m} / \mathrm{m})$ & 0.123 & 0.188 & 0.236 & 0.320 & 0.350 & 0.407 \\
\hline Heptamethylnonane $(\mathrm{m} / \mathrm{m})$ & 0.550 & 0.484 & 0.436 & 0.319 & 0.321 & 0.263 \\
\hline Decahydronaphthalene $(\mathrm{m} / \mathrm{m})$ & 0.327 & 0.328 & 0.328 & 0.361 & 0.329 & 0.330 \\
\hline 1-Methylnaphthalene $(\mathrm{m} / \mathrm{m})$ & 0.000 & 0.000 & 0.000 & 0.000 & 0.000 & 0.000 \\
\hline Cetane Number & 34.8 & 40.7 & 45.0 & 53.5 & 55.2 & 60.3 \\
\hline TSI & 19.0 & 18.2 & 17.6 & 16.6 & 16.2 & 15.5 \\
\hline LHV (MJ/kg) & 44.040 & 44.090 & 44.130 & 44.160 & 44.230 & 44.280 \\
\hline Density $(\mathrm{g} / \mathrm{ml})$ & 0.806 & 0.805 & 0.804 & 0.806 & 0.803 & 0.802 \\
\hline Kinematic Viscosity at $40^{\circ} \mathrm{C}(\mathrm{cSt})$ & 2.737 & 2.724 & 2.714 & 2.654 & 2.692 & 2.680 \\
\hline Molar H/C & 2.017 & 2.017 & 2.017 & 2.016 & 2.016 & 2.016 \\
\hline $\mathrm{T}_{10}\left({ }^{\circ} \mathrm{C}\right)$ & 215.3 & 216.5 & 217.0 & 216.5 & 219.2 & 220.7 \\
\hline $\mathrm{T}_{20}\left({ }^{\circ} \mathrm{C}\right)$ & 218.9 & 220.3 & 221.5 & 221.2 & 224.3 & 226.4 \\
\hline $\mathrm{T}_{30}\left({ }^{\circ} \mathrm{C}\right)$ & 222.9 & 224.9 & 226.6 & 226.8 & 231.3 & 233.6 \\
\hline $\mathrm{T}_{40}\left({ }^{\circ} \mathrm{C}\right)$ & 228.0 & 231.1 & 233.2 & 234.5 & 239.3 & 242.3 \\
\hline $\mathrm{T}_{50}\left({ }^{\circ} \mathrm{C}\right)$ & 234.1 & 237.8 & 241.0 & 244.3 & 248.9 & 252.8 \\
\hline $\mathrm{T}_{60}\left({ }^{\circ} \mathrm{C}\right)$ & 240.8 & 245.7 & 249.4 & 254.6 & 258.7 & 263.1 \\
\hline $\mathrm{T}_{70}\left({ }^{\circ} \mathrm{C}\right)$ & 247.4 & 253.6 & 257.4 & 264.6 & 267.1 & 271.6 \\
\hline $\mathrm{T}_{80}\left({ }^{\circ} \mathrm{C}\right)$ & 254.4 & 260.9 & 264.9 & 272.2 & 274.0 & 277.2 \\
\hline $\mathrm{T}_{90}\left({ }^{\circ} \mathrm{C}\right)$ & 261.7 & 268.9 & 272.6 & 278.5 & 279.6 & 281.4 \\
\hline
\end{tabular}


705 cetane numbers ranging from 35 to 60 (in increments of 5) and a TSI value of 31.

\begin{tabular}{|c|c|c|c|c|c|c|}
\hline Predicted Fuel Property & $\begin{array}{l}\text { CN35_- } \\
\text { TSI31 }\end{array}$ & $\begin{array}{l}\text { CN40_- } \\
\text { TSI31 }\end{array}$ & $\begin{array}{l}\text { CN45_- } \\
\text { TSI31 }\end{array}$ & $\begin{array}{l}\text { CN50_- } \\
\text { TSI31 }\end{array}$ & $\begin{array}{l}\text { CN55_ } \\
\text { TSI31 }\end{array}$ & $\begin{array}{l}\text { CN60_ } \\
\text { TSI31 }\end{array}$ \\
\hline n-Hexadecane (v/v) & 0.19 & 0.26 & 0.31 & 0.37 & 0.43 & 0.48 \\
\hline Heptamethylnonane (v/v) & 0.51 & 0.44 & 0.39 & 0.33 & 0.27 & 0.22 \\
\hline Decahydronaphthalene (v/v) & 0.20 & 0.18 & 0.19 & 0.18 & 0.18 & 0.18 \\
\hline 1-Methylnaphthalene (v/v) & 0.10 & 0.12 & 0.11 & 0.12 & 0.12 & 0.12 \\
\hline $\mathrm{n}$-Hexadecane $(\mathrm{m} / \mathrm{m})$ & 0.177 & 0.242 & 0.289 & 0.345 & 0.401 & 0.449 \\
\hline Heptamethylnonane $(\mathrm{m} / \mathrm{m})$ & 0.487 & 0.420 & 0.373 & 0.316 & 0.259 & 0.211 \\
\hline Decahydronaphthalene $(\mathrm{m} / \mathrm{m})$ & 0.216 & 0.194 & 0.205 & 0.195 & 0.195 & 0.195 \\
\hline 1-Methylnaphthalene $(\mathrm{m} / \mathrm{m})$ & 0.121 & 0.145 & 0.133 & 0.145 & 0.145 & 0.145 \\
\hline Cetane Number & 35.5 & 40.5 & 45.2 & 49.9 & 55.0 & 59.2 \\
\hline TSI & 31.1 & 32.8 & 30.9 & 31.5 & 30.8 & 30.3 \\
\hline LHV (MJ/kg) & 43.74 & 43.73 & 43.80 & 43.81 & 43.86 & 43.90 \\
\hline Density $(\mathrm{g} / \mathrm{ml})$ & 0.820 & 0.822 & 0.820 & 0.821 & 0.820 & 0.819 \\
\hline Kinematic Viscosity at $40^{\circ} \mathrm{C}(\mathrm{cSt})$ & 2.756 & 2.749 & 2.736 & 2.728 & 2.716 & 2.707 \\
\hline Molar H/C & 1.897 & 1.873 & 1.884 & 1.872 & 1.872 & 1.871 \\
\hline $\mathrm{T}_{10}\left({ }^{\circ} \mathrm{C}\right)$ & 224.1 & 226.8 & 227.0 & 229.2 & 230.9 & 231.8 \\
\hline $\mathrm{T}_{20}\left({ }^{\circ} \mathrm{C}\right)$ & 227.1 & 230.8 & 231.5 & 234.0 & 235.5 & 236.9 \\
\hline $\mathrm{T}_{30}\left({ }^{\circ} \mathrm{C}\right)$ & 231.4 & 234.5 & 236.0 & 238.9 & 241.2 & 243.1 \\
\hline $\mathrm{T}_{40}\left({ }^{\circ} \mathrm{C}\right)$ & 235.4 & 239.3 & 241.2 & 244.3 & 247.0 & 249.5 \\
\hline $\mathrm{T}_{50}\left({ }^{\circ} \mathrm{C}\right)$ & 239.9 & 244.3 & 246.9 & 250.1 & 254.0 & 256.9 \\
\hline $\mathrm{T}_{60}\left({ }^{\circ} \mathrm{C}\right)$ & 245.0 & 249.4 & 252.7 & 256.9 & 260.4 & 263.9 \\
\hline $\mathrm{T}_{70}\left({ }^{\circ} \mathrm{C}\right)$ & 250.7 & 255.4 & 259.5 & 263.4 & 267.2 & 270.2 \\
\hline $\mathrm{T}_{80}\left({ }^{\circ} \mathrm{C}\right)$ & 257.0 & 262.2 & 266.8 & 270.2 & 274.2 & 276.7 \\
\hline $\mathrm{T}_{90}\left({ }^{\circ} \mathrm{C}\right)$ & 265.7 & 271.7 & 274.8 & 277.7 & 279.9 & 281.8 \\
\hline
\end{tabular}



cetane numbers ranging from 35 to 60 (in increments of 5) and a TSI value of 48 .

\begin{tabular}{|c|c|c|c|c|c|c|}
\hline Predicted Fuel Property & $\begin{array}{l}\text { CN35 } \\
\text { TSI48 }\end{array}$ & $\begin{array}{l}\text { CN40_- } \\
\text { TSI48 }\end{array}$ & $\begin{array}{l}\text { CN45_- } \\
\text { TSI48 }\end{array}$ & $\begin{array}{l}\text { CN50_- } \\
\text { TSI48 }\end{array}$ & $\begin{array}{l}\text { CN55 } \\
\text { TSI48 }\end{array}$ & $\begin{array}{l}\text { CN60_ } \\
\text { TSI48 }\end{array}$ \\
\hline n-Hexadecane (v/v) & 0.26 & 0.32 & 0.38 & 0.42 & 0.50 & 0.56 \\
\hline Heptamethylnonane (v/v) & 0.44 & 0.38 & 0.32 & 0.25 & 0.20 & 0.14 \\
\hline Decahydronaphthalene (v/v) & 0.05 & 0.05 & 0.05 & 0.06 & 0.05 & 0.04 \\
\hline 1-Methylnaphthalene $(\mathrm{v} / \mathrm{v})$ & 0.25 & 0.25 & 0.25 & 0.27 & 0.25 & 0.26 \\
\hline $\mathrm{n}$-Hexadecane $(\mathrm{m} / \mathrm{m})$ & 0.238 & 0.293 & 0.349 & 0.384 & 0.460 & 0.515 \\
\hline Heptamethylnonane $(\mathrm{m} / \mathrm{m})$ & 0.413 & 0.357 & 0.301 & 0.234 & 0.189 & 0.132 \\
\hline Decahydronaphthalene $(\mathrm{m} / \mathrm{m})$ & 0.053 & 0.053 & 0.053 & 0.063 & 0.053 & 0.043 \\
\hline 1-Methylnaphthalene $(\mathrm{m} / \mathrm{m})$ & 0.296 & 0.297 & 0.297 & 0.319 & 0.298 & 0.310 \\
\hline Cetane Number & 34.8 & 39.9 & 45.0 & 48.4 & 55.2 & 59.9 \\
\hline TSI & 48.8 & 48.1 & 47.5 & 48.9 & 46.2 & 46.8 \\
\hline LHV (MJ/kg) & 43.290 & 43.340 & 43.380 & 43.310 & 43.470 & 43.490 \\
\hline Density $(\mathrm{g} / \mathrm{ml})$ & 0.842 & 0.841 & 0.840 & 0.845 & 0.839 & 0.839 \\
\hline Kinematic Viscosity at $40^{\circ} \mathrm{C}(\mathrm{cSt})$ & 2.788 & 2.776 & 2.765 & 2.720 & 2.742 & 2.734 \\
\hline Molar H/C & 1.725 & 1.724 & 1.724 & 1.693 & 1.723 & 1.711 \\
\hline $\mathrm{T}_{10}\left({ }^{\circ} \mathrm{C}\right)$ & 239.1 & 240.4 & 241.8 & 241.8 & 245.0 & 248.0 \\
\hline $\mathrm{T}_{20}\left({ }^{\circ} \mathrm{C}\right)$ & 240.6 & 242.1 & 244.3 & 244.2 & 247.7 & 250.6 \\
\hline $\mathrm{T}_{30}\left({ }^{\circ} \mathrm{C}\right)$ & 242.1 & 244.3 & 246.6 & 246.8 & 250.7 & 253.5 \\
\hline $\mathrm{T}_{40}\left({ }^{\circ} \mathrm{C}\right)$ & 244.3 & 246.7 & 249.1 & 249.4 & 254.0 & 256.7 \\
\hline $\mathrm{T}_{50}\left({ }^{\circ} \mathrm{C}\right)$ & 246.7 & 249.3 & 251.9 & 252.5 & 257.1 & 259.8 \\
\hline $\mathrm{T}_{60}\left({ }^{\circ} \mathrm{C}\right)$ & 249.3 & 252.0 & 255.1 & 256.8 & 261.8 & 264.5 \\
\hline $\mathrm{T}_{70}\left({ }^{\circ} \mathrm{C}\right)$ & 252.4 & 256.6 & 259.8 & 261.9 & 267.1 & 269.6 \\
\hline $\mathrm{T}_{80}\left({ }^{\circ} \mathrm{C}\right)$ & 258.0 & 262.3 & 266.9 & 268.9 & 273.6 & 275.8 \\
\hline $\mathrm{T}_{90}\left({ }^{\circ} \mathrm{C}\right)$ & 267.8 & 272.4 & 276.2 & 277.6 & 280.4 & 282.1 \\
\hline
\end{tabular}

